\title{
Systematics of putative euparkeriids (Diapsida: Archosauriformes) from the Triassic of China
}

The South African species Euparkeria capensis is of great importance for understanding the early radiation of archosauromorphs (including archosaurs) following the Permo-Triassic mass extinction, as most phylogenetic analyses place it as the sister taxon to crown group Archosauria within the clade Archosauriformes. Although a number of species from Lower-Middle Triassic deposits worldwide have been referred to the putative clade Euparkeriidae, the monophyly of Euparkeriidae is controversial and has yet to be demonstrated by quantitative phylogenetic analysis. Three Chinese taxa have been recently suggested to be euparkeriids: Halazhaisuchus qiaoensis, 'Turfanosuchus' shageduensis, and Wangisuchus tzeyii, all three of which were collected from the Middle Triassic Ermaying Formation of northern China. Here, we reassess the taxonomy and systematics of these taxa. We regard Wangisuchus tzeyii as a nomen dubium, because the holotype is undiagnostic and there is no convincing evidence that the previously referred additional specimens represent the same taxon as the holotype. We also regard 'Turfanosuchus' shageduensis as a nomen dubium as we are unable to identify any diagnostic features. We refer the holotype to Archosauriformes, and more tentatively to Euparkeriidae. Halazhaisuchus qiaoensis and the holotype of 'Turfanosuchus shageduensis' are resolved as sister taxa in a phylogenetic analysis, and are in turn the sister taxon to Euparkeria capensis, forming a monophyletic Euparkeriidae that is the sister to Archosauria+Phytosauria. This is the first quantitative phylogenetic analysis to recover a non-monospecific, monophyletic Euparkeriidae, but euparkeriid monophyly is only weakly supported and will require additional examination. Given their similar sizes, stratigraphic positions and phylogenetic placement, the holotype of 'Turfanosuchus shageduensis' may represent a second individual of Halazhaisuchus qiaoensis, but no apomorphies or unique character combination can be identified to unambiguously unite 
the two. Our results have important implications for understanding the species richness and palaeobiogeographical distribution of early archosauriforms. 


\section{PeerJ Reviewing Manuscript}

1 Title: Systematics of putative euparkeriids (Diapsida: Archosauriformes) from the Triassic of

2 China

3

4 Authors and affiliations:

5 Roland B. Sookias ${ }^{1,2}$, Corwin Sullivan ${ }^{3}$, Jun Liu ${ }^{3}$, Richard J. Butler ${ }^{1,2}$

1. School of Geography, Earth and Environmental Sciences, University of Birmingham, Edgbaston, Birmingham B15 2TT, UK; email: sookias.r.b@gmail.com; phone: +441214146152

2. GeoBio-Center, Ludwig-Maximilians-Universität München, Richard-Wagner-Str. 10, 80333 Munich, Germany

3. Key Laboratory of Vertebrate Evolution and Human Origins of Chinese Academy of Sciences, Institute of Vertebrate Paleontology and Paleoanthropology, Chinese Academy of Sciences, 100044 Beijing, China

Corresponding author: Roland B. Sookias; address: School of Geography, Earth and Environmental Sciences, University of Birmingham, Edgbaston, Birmingham B15 2TT, UK; email: sookias.r.b@gmail.com; phone: +441214146152

Abstract: The South African species Euparkeria capensis is of great importance for understanding the early radiation of archosauromorphs (including archosaurs) following the Permo-Triassic mass extinction, as most phylogenetic analyses place it as the sister taxon to crown group Archosauria within the clade Archosauriformes. Although a number of species from Lower-Middle Triassic deposits worldwide have been referred to the putative clade Euparkeriidae, the monophyly of Euparkeriidae is controversial and has yet to be demonstrated by quantitative phylogenetic analysis. Three Chinese taxa have been recently suggested to be euparkeriids: Halazhaisuchus qiaoensis, 'Turfanosuchus shageduensis', and 'Wangisuchus tzeyii', all three of which were collected from the Middle Triassic Ermaying Formation of northern China. Here, we reassess the taxonomy and systematics of these taxa. We regard 'Wangisuchus tzeyii' as a nomen dubium, because the holotype is undiagnostic and there is no convincing evidence that the previously referred additional specimens represent the same taxon as the holotype. We also regard 'Turfanosuchus shageduensis' as a nomen dubium as we are unable to identify any diagnostic features. We refer the holotype to Archosauriformes, and more tentatively to Euparkeriidae. Halazhaisuchus qiaoensis and the holotype of 'Turfanosuchus shageduensis' are resolved as sister taxa in a phylogenetic analysis, and are in turn the sister taxon to Euparkeria capensis, forming a monophyletic Euparkeriidae that is the sister to 
Archosauria+Phytosauria. This is the first quantitative phylogenetic analysis to recover a nonmonospecific, monophyletic Euparkeriidae, but euparkeriid monophyly is only weakly supported and will require additional examination. Given their similar sizes, stratigraphic positions and phylogenetic placement, the holotype of 'Turfanosuchus shageduensis' may represent a second individual of Halazhaisuchus qiaoensis, but no apomorphies or unique character combination can be identified to unambiguously unite the two. Our results have important implications for understanding the species richness and palaeobiogeographical distribution of early archosauriforms.

Keywords: Euparkeriidae, Archosauriformes, Triassic, China, Euparkeria

\section{Main text:}

\section{Introduction}

Euparkeria capensis from the Cynognathus Assemblage Zone (Middle Triassic: Anisian) of South Africa (Ewer, 1965; Sookias \& Butler, 2013) is a key species of early archosauriform that is widely regarded as approaching the ancestral archosaur body plan (e.g. Romer, 1972c; Norman \& Weishampel, 1991; Parrish, 1997). Euparkeria capensis falls immediately outside of or very close to Archosauria in most phylogenetic studies (e.g. Bennett, 1996; Gower \& Wilkinson, 1996; Benton, 1999; Nesbitt, 2009; Brusatte et al., 2010; Ezcurra, Lecuona \& Martinelli, 2010; Nesbitt, 2011; Butler et al. 2014; Ezcurra, Scheyer \& Butler 2014), and has been used as an outgroup in numerous studies of archosaur phylogeny and morphological evolution (e.g. Perry, 1992; Carrier \& Farmer, 2000; Hutchinson, 2001a, 2001b; Marugán-Lobón \& Buscalioni, 2003; Nesbitt, 2003; Rauhut, 2003; Seymour et al., 2004; de Ricqlès et al., 2008; Sullivan, 2010; Maidment \& Barrett, 2011; Butler, Barrett \& Gower, 2012; Foth \& Rauhut 2013). Several other taxa from LowerMiddle Triassic deposits around the world have historically been assigned to the group Euparkeriidae (see below; reviewed by Sookias \& Butler, 2013; see also Sookias et al., in press), although no cladistic analysis has yet recovered this taxon as a monophyletic, non-monospecific entity. Most previous quantitative phylogenetic analyses of basal archosauriforms have not tested the monophyly of Euparkeriidae, because they have not included putative euparkeriid species from Poland, Russia and China (Sookias and Butler, 2013; but see Sookias et al., in press). The inclusion of these putative euparkeriid species in phylogenetic analyses has been hampered by the often fragmentary nature of their remains, and an ongoing lack of clarity with regard to their taxonomy and anatomy (Gower \& Sennikov, 2000; Sookias \& Butler, 2013). 
Three Chinese taxa from the Anisian Ermaying Formation (see Table S2 for names in

74

75

76

77

78

79

80

81

82 Chinese characters and Pinyin, as well as previously used romanizations) of north central China have been recently considered as putative euparkeriids worthy of further investigation (Sookias \& Butler, 2013): 'Wangisuchus tzeyii’ Young, 1964, Halazhaisuchus qiaoensis Wu, 1982, and 'Turfanosuchus shageduensis' Wu, 1982. However, the phylogenetic relationships of these Chinese putative euparkeriids to each other, and to other archosauriforms, have never previously been tested. Given the pivotal phylogenetic position of Euparkeria capensis, testing the affinities of these taxa has the potential to clarify the relationships of major clades of early archosauriforms and patterns of character evolution during the rise of Archosauria. Here we revise the taxonomy and review the anatomy of the Chinese putative euparkeriids. We also conduct a novel phylogenetic analysis of early archosauriforms that includes two of these taxa, shedding new light on their systematic positions.

\section{Taxonomic history of the Chinese euparkeriids}

The three species discussed here all derive from the Ermaying Formation of China and were referred to Euparkeriidae in their original descriptions. 'Wangisuchus tzeyii' from the upper Ermaying Formation was described by Young (1964) and referred to Euparkeriidae because of supposed similarities in the maxilla and pelvic girdle to Euparkeria capensis. 'Wangisuchus tzeyii' has often been subsequently considered to represent a "rauisuchian" or other pseudosuchian (i.e. a member of the 'crocodile-line' of Archosauria), based primarily on the presence of a suchian calcaneum within material assigned to the taxon based solely on provenance and broad morphological compatibility (e.g. Welles \& Long, 1974; Krebs, 1976; Parrish, 1992; Gower, 2000; Gower \& Sennikov, 2000; Borsuk-Białynicka \& Sennikov, 2009; Nesbitt, 2011; Nesbitt et al., 2013). However, the species has never been adequately reassessed (Sookias \& Butler 2013) and various authors have continued to consider 'Wangisuchus tzeyii' a possible euparkeriid and utilize this referral in biogeographic and biostratigraphic analyses (e.g. Sennikov, 1989a, Sennikov, 1989b; Shubin \& Sues, 1991; Lucas, 1998, 2001). The species was cited as one of the earliest records of any archosaur (as a "rauisuchian") by Benton \& Donoghue (2007), and used as evidence for constraining the timing of the crocodile-bird split.

Halazhaisuchus qiaoensis and 'Turfanosuchus shageduensis' were described by Wu (1982) and referred to Euparkeriidae based on similarities to Euparkeria capensis, including plesiomorphies such as retention of intercentra and a "large coracoid" (Wu, 1982, p. 20). Zhen et al. (1985) considered Halazhaisuchus qiaoensis to be a "thecodont" relatively closely related to 
107 the proterosuchid Chasmatosaurus yuani, although no anatomical justification for this was given.

108 Sennikov (1989a, 1989b) referred Halazhaisuchus qiaoensis, 'Turfanosuchus shageduensis' and

109 'Wangisuchus tzeyii' (as well as Xilousuchus sapingensis; see below) to the putative euparkeriid

110 subgroup Dorosuchinae, along with Dorosuchus neoetus from the Middle Triassic of Russia. The

111 basis for the referral was that these taxa were supposedly more robust than Euparkeria capensis.

112 Parrish (1993) was apparently confusing Halazhaisuchus qiaoensis with 'Turfanosuchus

113 shageduensis' when he stated that the latter was a primitive archosauriform distinct from

114 Turfanosuchus dabanensis based on the presence of vertebral intercentra "and other features"

115 (Parrish, 1993, p. 297), given that intercentra are present in Halazhaisuchus qiaoensis but not in

116 'Turfanosuchus shageduensis'. Lucas (2001) considered both Halazhaisuchus qiaoensis and

117 'Turfanosuchus shageduensis' as euparkeriids, together with 'Wangisuchus tzeyii' and

118 Euparkeria capensis (see also Lucas, 1998). Wu \& Russell (2001) compared the anatomy of

119 Halazhaisuchus qiaoensis and 'Turfanosuchus shageduensis' to that of Turfanosuchus

120 dabanensis. They noted resemblances in humeral and femoral morphology between the first two

121 species and Turfanosuchus dabanensis, but also identified differences including the presence of

122 intercentra in Halazhaisuchus qiaoensis and discrepancies in osteoderm morphology between

123 Halazhaisuchus qiaoensis and Turfanosuchus dabanensis. Borsuk-Białynicka \& Evans (2003)

124 tentatively supported the referral of Halazhaisuchus qiaoensis to Euparkeriidae, whereas Borsuk-

125 Białynicka \& Evans (2009) regarded the euparkeriid affinities of the taxon as doubtful.

126 Several other taxa from the Chinese Triassic and Lower Jurassic have historically been

127 assigned to Euparkeriidae but are no longer regarded as potential members of the group and are

128 not discussed in detail here. Xilousuchus sapingensis Wu, 1981 was assigned to Euparkeriidae by

129 Sennikov (1989a, 1989b), but recent analyses have reidentified it as a ctenosauriscid poposauroid

130 (Nesbitt, Liu, \& Li, 2011; Butler et al., 2011; Nesbitt, 2011). Platyognathus hsui Young, 1944

131 was referred to Euparkeriidae by Huene (1956), but this taxon is a crocodyliform (Wu \& Sues,

132 1996). Turfanosuchus dabanensis Young, 1973 was initially assigned to Euparkeriidae, but was

133 regarded by Parrish (1993) as a suchian. The species was redescribed by Wu \& Russell (2001) as

134 a non-pseudosuchian not closely related to E. capensis, but was placed in Pseudosuchia by the

135 most recent and extensive phylogenetic analysis of Archosauriformes (Nesbitt, 2011), and has

136 since been identified as a member of the pseudosuchian clade Gracilisuchidae (Butler et al.,

137 2014). 'Fukangolepis' barbaros Young 1978 was mentioned as having been referred to

138 Euparkeriidae by Parrish (1986) but presumably this was a lapsus calami given that the holotype

139 of the species is an indeterminate dicynodont skull fragment (Lucas \& Hunt, 1993) assigned by 
140 Young (1978) to Aetosauria; the fact that Parrish (1986) cites Young (1973) for this assertion

141 indicates Parrish may have confused 'Fukangolepis' barbaros with Turfanosuchus dabanensis.

142 Finally, Yonghesuchus sangbiensis Wu, Liu \& Li, 2001 was listed without discussion as a

143 euparkeriid by Wu \& Sun (2008), but this taxon is also a gracilisuchid pseudosuchian (Butler et

144 al., 2014).

145

146

Geological and geographic setting (Fig. 1)

148 All of the Chinese putative euparkeriid specimens discussed here are from the Ermaying

149 Formation. The Ermaying Formation was deposited during the Triassic in a meandering fluvial

150 environment with an east to west palaeocurrent (Liu et al., 2012). The Ermaying Formation is

151 within the Ordos basin, and is overlain by the Tongchuan Formation (Liu, Li \& Li 2013). The

152 specimens assigned to Halazhaisuchus qiaoensis (IVPP V6027) and 'Turfanosuchus

153 shageduensis' (IVPP V6028) are from the sandstones of the lower Ermaying Formation, which is

154 made up of yellowish pink, yellowish green, and greyish white quartz arkose (Yin, 2003). The

155 lower Ermaying Formation has been considered early Anisian in age as a result of long-range

156 biostratigraphic correlation with Subzone B of the Cynognathus Assemblage Zone of South

157 Africa, based primarily on the presence of the dicynodont Kannemeyeria (Rubidge, 2005;

158 Fröbisch, 2009). Dating of Subzone B of the Cynognathus Assemblage Zone is itself based on

159 long-range vertebrate biostratigraphy (Hancox, 2000). Lucas (2001) argued for an Olenekian age

160 for the lower Ermaying based on the presence of the dicynodont Shansiodon in the upper

161 Ermaying (see below). Sues \& Fraser (2010) concurred with this age assessment, based on a

162 proposed correlation of the upper Heshanggou Formation of northern China with the lower

163 Ermaying Formation and the presence of the typically Olenekian spore-bearing tree Pleuromeia

164 sternbergii in the former. However, Butler et al. (2011) noted that Pleuromeia sternbergii extends

165 into the early Anisian in Germany, and that at least part of the Heshanggou Formation may be

166 Anisian in age. Using sensitive, high-resolution ion microprobe (SHRIMP) U-Pb dating, the age

167 of the upper Ermaying Formation (Member II) was recently found to be $245.9 \pm 3.2 \mathrm{Ma}$ (Liu, Li

$168 \& \mathrm{Li}, 2013)$. Although the range of error encompasses the entire Anisian (currently dated as

169 247.2-242 Ma: Ogg 2012; Cohen, Finney \& Gibbard, 2013), this result is consistent with an

170 Anisian age for the upper Ermaying, and by inference an early Anisian or late Olenekian date for

171 the lower Ermaying and Heshanggou formations.

$172 \quad$ All material referred to 'Wangisuchus tzeyii' is from the white sandstones and mudstones

173 of the upper Ermaying Formation. Rubidge (2005) and Hancox, Angielczyk \& Rubidge (2013) 
174 assigned the upper Ermaying Formation to the late Anisian based on the presence of the

175 dicynodont Shansiodon. The same genus occurs in Subzone C of the Cynognathus Assemblage

176 Zone of South Africa (Hancox, Angielczyk \& Rubidge, 2013), and the shansiodont Vinceria

177 occurs in the Río Mendoza and Upper Puesto Viejo formations of Argentina (Hancox, 1998;

178 Renaut \& Hancox, 2001; Domnanovich \& Marsicano 2012). The proposed late Anisian date for

179 Subzone C of the Cynognathus Assemblage Zone is itself based on long-range vertebrate

180 biostratigraphy (Hancox, 2000). The upper Ermaying Formation was referred to the Perovkan

181 land-vertebrate faunochron by Lucas (2010), again based upon vertebrate biostratigraphy. As

182 noted above, new SHRIMP analyses suggest an Anisian age for the upper Ermaying Formation.

184 Terminology and methods

185

We use the limb orientation terminology of Gower (2003), which combines that of Romer

187 (1942) and that of Rewcastle (1980). This orientation corresponds to a fully anteriorly extended

188 hindlimb (the anterior surfaces of hindlimb bones in descriptions of fully erect taxa such as

189 dinosaurs thus correspond to the dorsal surfaces in our terminology), and a forelimb with the

190 humerus fully extended posteriorly and the epipodials fully extended anteriorly (the anterior

191 surfaces of forelimb bones in fully erect taxa thus correspond to the ventral surface of the

192 humerus and to the dorsal surfaces of the radius and ulna here). The scapula is described with the

193 shaft held vertically. We use the terminology of Wilson (1999) for vertebral laminae and that of

194 Wilson et al. (2011) for vertebral fossae.

195 Phylogenetic analyses were carried out using the matrix of Butler et al. (2014), modified

196 from Nesbitt (2011), with Halazhaisuchus qiaoensis and 'Turfanosuchus shageduensis' (not

197 previously included by Nesbitt [2011] or Butler et al. [2014]) included in separate analyses as

198 both distinct taxa and as a combined taxon. Additionally, we changed the scoring of osteoderm

199 shape in Euparkeria capensis from that used by Nesbitt (2011: character 407) from "square-

200 shaped, about equal dimensions" to "longer than wide" (see Discussion). The analyses were

201 conducted in TNT v. 1.1 (Goloboff, Farris \& Nixon, 2003, 2008). We employed the same

202 methodology as Nesbitt (2011), eliminating the same taxa from the dataset prior to analysis, with

203 the same characters treated as ordered, and using equally weighted parsimony. An initial search

204 using the "New Technology search" option was carried out using sectorial search, ratchet and

205 tree-fusing options with default parameters. Minimum tree length was obtained for 1000 separate

206 replicates and the trees were stored in RAM. A heuristic tree search was then conducted using the

207 stored trees, followed by TBR branch swapping. Standard bootstrap values and Bremer support 
208 values (decay indices) were calculated for each node using the inbuilt functionality of TNT and

209 the BREMER script respectively.

210

211

Institutional abbreviations

212

213 AMNH, American Museum of Natural History, New York, USA; BPI, Bernard Price

214 Institute for Palaeontological Research, Johannesburg, South Africa; IVPP,

215 Institute of Vertebrate Paleontology and Paleoanthropology, Chinese Academy of Sciences,

216 Beijing, China; NHMUK, Natural History Museum, London, UK; NM, National Museum,

217 Bloemfontein, South Africa; PEFO, Petrified Forest National Park, Arizona, USA; PIN,

218 Paleontological Institute of the Russian Academy of Sciences, Moscow, Russia;

219 PVL, Istituto Miguel Lillo, Tucumán, Argentina SAM, Iziko South African Museum,

220 Cape Town, South Africa; SMNS, Staatliches Museum für Naturkunde, Stuttgart, Germany;

221 TTU, Texas Tech University Museum, Lubbock,Texas, U.S.A.; UFRGS, Institute

222 of Geosciences, Federal University of Rio Grande do Sul, Porte Alegre, Brazil;

223 UMZC, University Museum of Zoology, Cambridge, UK; USNM, National Museum of

224 Natural History, Washington, DC, USA.

225

226

227

228

229

230

231

232

233

234

235

236

237

238

239

240

241

242

243

244 Ermaying Formation of Shanxi Province (Middle Triassic: Anisian). IVPP V2701 (holotype) and

245 IVPP V2702-V2704 (paratypes) are from locality 56173, Xishiwa near Louzeyu Village, 
246 Wuxiang County (Fig. 1). This locality has been entered in the Paleobiology Database as number

247 101059. See Geological Setting for further information.

249 Remarks. The holotype maxilla, IVPP V2701 (Fig. 2A-B), is fragmentary and undiagnostic, as

250 are the paratype specimens. Whilst the presence of alveoli and interdental plates indicates

251 thecodont tooth implantation (a synapomorphy of Erythrosuchus +Archosauria: Nesbitt, 2011),

252 neither a suite of autapomorphies nor a unique combination of character states can be identified

253 in the maxilla. The original diagnosis presented by Young (1964) was inadequate for a number of

254 reasons: it referred to the "long and low" shape of the maxilla, but the holotype maxilla does not

255 differ in this regard from those of most early archosauriforms; the posterior process of the maxilla

256 was described as "pointed", but is in fact incomplete; the anterior margin of the maxilla was

257 described as "rounded" but is also incomplete; and teeth and other elements not preserved in the

258 holotype were used in the diagnosis, but there is no convincing case for referring these elements

259 to the same taxon as the holotype. We therefore consider 'Wangisuchus tzeyii' to be a nomen

260 dubium. The most exclusive phylogenetic placement that can be reasonably supported for the

261 holotype is Archosauriformes indet., based on the inferred presence of thecodont dental

262 implantation in the maxilla. As noted above, this feature supports a position crownward of

263 Proterosuchus (Nesbitt, 2011).

264 Young (1964) referred many isolated and poorly preserved postcranial elements from the

265 type locality and other localities in the same region to 'Wangisuchus tzeyii', but first-hand

266 inspection of much of this material revealed it to be undiagnostic. Furthermore, there are no

267 compelling similarities to justify regarding even the two relatively complete paratype maxillae

268 (IVPP V2703, V2704; Fig. 2D-E) as necessarily conspecific with the holotype, and in fact both

269 of these paratype maxillae appear to differ from the holotype in having a convex rather than

270 straight anterodorsal margin (Fig. 2, adm). As discussed by several authors (Kuhn, 1976; Parrish,

271 1993; Gower \& Sennikov, 2000; Nesbitt, 2011), an unnumbered calcaneum within this previously

272 referred material demonstrably belongs to a suchian archosaur, but there is no evidence beyond

273 the holotype and the calcaneum hailing from the same locality (and the generally compatible

274 size) to support the referral of this calcaneum to 'Wangisuchus tzeyii'.

275

276

277

278

279

280

281

EUPARKERIIDAE Huene, 1920 sensu Sookias \& Butler, 2013

Halazhaisuchus Wu, 1982

Type and only species. Halazhaisuchus qiaoensis $\mathrm{Wu}, 1982$. 
Holotype. IVPP V6027 (Figs. 3-7), posterior three cervical and anterior three dorsal vertebrae in articulation with osteoderms and incomplete ribs (V6027-1), seven dorsal vertebrae in articulation with osteoderms (V6027-2), left (V6027-3) and right (V6027-4) scapulae, left (V6027-3) and partial right (V6027-4) coracoids, right humerus (V6027-5), ulna (V6027-6), and radius (V6027-7), an isolated left cervical rib (V6027-8), and an isolated median osteoderm (V6027-9). All material probably pertains to a single individual.

Horizon and locality. IVPP V6027 is from Fugu County, Shaanxi Province, China (Fig. 1). It is from the lower Ermaying Formation (Lower or Middle Triassic: late Olenekian or early Anisian), Paleobiology Database locality number 100138. See Geological Setting for further information.

Original diagnosis (paraphrased from Wu, 1982, p. 300). Relatively small pseudosuchian. Pectoral girdle well developed. Scapula exceptionally elongated and strongly expanded at both ends; ratio of scapula length to humerus length over 1.15:1; oval muscle-attachment area above glenoid with notably projecting ridge. Coracoid very large, forming two thirds of glenoid. Humerus robust, terminating in triangularly expanded apex proximally due to well-developed deltopectoral crest along proximal quarter of shaft. Radius and ulna slender, ulna with welldeveloped olecranon process. Vertebrae slightly amphicoelous, with elongated centra and low neural spines expanded distally; presacral vertebrae with intercentra. Cervical and anterior dorsal ribs three-headed. Row of dorsal scutes on either side of midline, scutes overlap one another and are leaf-like in outline; posterior ends of scutes grooved ventrally; in cervical and anterior dorsal regions scutes from both sides are sutured together firmly. two autapomorphies: (1) strongly pronounced tuber on the scapula, for attachment of the scapular head of the m. triceps, that is circular in outline when the scapula is in lateral view, with the apex of the tuber slightly depressed (similar tubera in other taxa differ in shape, being teardrop shaped and lacking a depression, e.g. Batrachotomus kupferzellensis - Gower \& Schoch 2009); (2)

312 pronounced muscle attachment scar on the scapula in the form of a depressed strip on the lateral

313 surface of the blade running from anterodorsal to posteroventral, beginning at an abrupt kink in

314 the anterior margin at around midlength of the blade. The species is further diagnosable by the

315 following unique combination of characters: two rows of paramedian scutes with exposed 316 surfaces at least twice as long as wide when articulated, tapering anterior processes and broad, 
317 rounded posterior margins, each having a longitudinal keel closer to the medial margin than the

318 lateral one; large flattened flange projecting from the proximal part of the anterior margin of each

319 cervical rib; presence of a tuber on the scapula for attachment of the scapular head of the $m$.

320 triceps; presence of dorsal intercentra; epipophyses on cervical vertebrae.

321 The same osteoderm shape and arrangement is found in Euparkeria capensis and in some

322 pseudosuchians (e.g. Ticinosuchus ferox - Krebs 1965; Rauisuchus tiradentes - Lautenschlager

323 2008), but differs from other stem and early crown archosaurs including proterochampsids (e.g.

324 Chanaresuchus bonapartei - PVL 4575; single row of scutes wider than long), doswelliids (e.g.

325 Doswellia kaltenbachi - Dilkes \& Sues 2009; multiple rows of shorter, anteriorly blunt, and more

326 strongly sculpted scutes), and many pseudosuchians (e.g. Batrachotomus kupferzellensis - Gower

$327 \&$ Schoch 2009 - scutes are either wider than long, lack a dorsal keel, or are blunt anteriorly;

328 Saurosuchus galilei - Trotteyn, Desojo \& Alcober 2011 - exposed length of each osteoderm is

329 shorter than the width or around the same as the width). An expanded flattened cervical rib flange

330 is present in some crown taxa (e.g. Batrachotomus kupferzellensis - Gower \& Schoch 2009,

331 Gracilisuchus stipanicicorum - Romer 1972b), but is absent in most stem taxa (e.g. Euparkeria

332 capensis - SAM-PK-5867, Proterochampsa barrionuevoi-MCZ 3408, Doswellia kaltenbachi-

333 Dilkes \& Sues 2009). A marked scapular tuber for attachment of the $m$. triceps is otherwise

334 confined to the crown and Phytosauria (e.g. Batrachotomus kupferzellensis - Gower \& Schoch

335 2009; Parasuchus hislopi - Nesbitt 2011). Dorsal intercentra are absent in crown taxa (Nesbitt

336 2011), differentiating Halazhaisuchus qiaoensis from pseudosuchian taxa with the same

337 osteoderm shape (Krebs 1965, Lautenschlager 2008, Lautenschlager \& Desojo 2011).

338 Pseudosuchian taxa with the same osteoderm shape as Halazhaisuchus also lack cervical

339 epipophyses (Krebs 1965, Lautenschlager 2008, Lautenschlager \& Desojo 2011).

340

341 Remarks. The original differential diagnosis of Halazhaisuchus qiaoensis was insufficient

342 because it did not adequately distinguish the taxon from other stem- and early archosaurs. Many

343 features listed (e.g. "pectoral girdle well-developed") were not sufficiently clear or distinct to be

344 effective in diagnosing the taxon. Other features are shared with other taxa: leaf-shaped

345 osteoderms and presacral intercentra are shared with Euparkeria capensis (Ewer, 1965), and the

346 vertebral features listed in the original diagnosis are essentially also shared with Euparkeria

347 capensis (Ewer, 1965; UMZC T.692).

348

349

350

\section{Description}


351 Cervical vertebrae. IVPP V6027-1 (Fig. 3A-E) includes what we identify as the articulated

352 posterior three cervical vertebrae (in articulation with what we identify as the anterior three

353 dorsals; the exact point of the cervical-dorsal transition is hard to pinpoint with certainty). The

354 neurocentral sutures are fused. The centra of the cervical vertebrae are spool-shaped and longer

355 than tall (as in Euparkeria capensis - SAM-PK-5867 and proterochampsids - Romer 1972a - but

356 contrasting with erythrosuchids - Gower 2003 - and many crown taxa - Gower \& Schoch 2009),

357 with a low ventral keel. As in Euparkeria (SAM-PK-5867) and most early archosauriforms (e.g.

358 Dilkes \& Sues 2009; Gower \& Schoch 2009; Romer 1972a), in the anterior cervicals the

359 diapophysis (Fig. 3A, di) is placed near the anterodorsal corner of the centrum, and the

360 parapophysis (Fig. 3A, pa) is placed near the anteroventral corner; posteriorly along the column

361 the diapophysis moves posterodorsally, the parapophysis moves dorsally to approximately

362 halfway up the centrum, and the two become connected by a variably developed

363 paradiapophyseal lamina (Fig. 3A, ppdl). A thick, rounded prezygadiapophyseal lamina (Fig. 3A,

364 prdl) connects the prezygapophysis and the diapophysis as in Euparkeria capensis (SAM-PK-

365 5867) and crown taxa (Gower \& Schoch 2009), but contrasting with some more basal taxa (e.g.

366 Proterosuchus fergusi-NMQR 1484). A shallow spinodiapophyseal fossa (Fig. 3A, sdf) is

367 present immediately dorsal to the diapophysis, as seen in Euparkeria capensis, but less strongly

368 developed than in crown taxa (e.g. Gower \& Schoch 2009) and erythrosuchids (e.g. Gower

369 2003). The anterior and posterior articular facets of the centra are gently concave and subcircular,

370 as in most early archosauriforms (e.g. Ewer 1965, Gower \& Schoch 2009, Gower 2003, Romer

371 1972a).

372 Some of the postzygapophyses bear epipophyses (Fig. 3A, ep), but these do not extend

373 posteriorly beyond the postzygapophyseal articular surfaces. The presence of epipophyses

374 contrasts with all stem archosaurs excluding Mesosuchus and Vancleavea, but is common in the

375 crown (Nesbitt 2011). As in many other taxa with dorsal scutes (e.g. Euparkeria capensis - SAM-

376 PK-K8050, Batrachotomus kupferzellensis - Gower \& Schoch 2009, Jaxtasuchus salomoni -

377 SMNS 91412), but contrasting with proterochampsids (Romer 1972a) and taxa lacking

378 osteoderms (e.g. erythrosuchids - Gower 2003), the neural spines (Fig. 3A-B, ns) widen

379 transversely towards their distal ends to form broad, flat spine tables, each of which attains its

380 maximum transverse width at a point slightly anterior to the midlength as in Euparkeria capensis

381 (SAM-PK-K8050). As in Euparkeria capensis (UMZC T.692), the pre- and postzygapophyseal

382 facets are slightly elongated ellipses in dorsal view, with the long axis of the prezygapophyseal

383 facets running posteromedial-anterolateral, and that of the postzygapophyseal facets running 
384 posterolateral-anteromedial; the prezygapophyseal facets face anterodorsomedially and the

385 postzygapophyseal facets face posteroventrolaterally. Unlike in most stem taxa (e.g.

386 Erythrosuchus, Proterosuchus - Nesbitt 2011) and some specimens of Euparkeria capensis (e.g.

387 SAM-PK-6047A), but as in proterochampsids (e.g. Chanaresuchus barrionuevoi - SMNS 91412;

388 Nesbitt 2011) and crown taxa (Nesbitt 2011), no intercentra can be identified between the

389 cervical vertebrae, although their absence could be preservational.

390

391

Cervical ribs. IVPP V6027-1 (Fig. 3A-E) includes three partial cervical ribs in articulation with

392 vertebrae and IVPP V6027-8 (Fig. 4A-B) consists of a single left cervical rib. The cervical ribs are two-headed, as in Euparkeria capensis (SAM-PK-5867) and most stem and crown archosaurs (e.g. Smilosuchus gregorii -USNM 18313, Batrachotomus kupferzellensis - Gower \& Schoch, 2009, Proterosuchus fergusi - Cruickshank 1972), and their shafts extend posteriorly, ventrally and laterally and are gently curved posteriorly, especially towards their distal ends. The tuberculum is longer than the capitulum (Fig. 4, tub, cap) and is directed medially whereas the capitulum is directed anteromedially. A dorsoventrally thin flange (Fig. 4, fl), which widens transversely as it continues proximally, extends along the anterolateral margin of each rib. A similar structure is present in several other archosauriforms, including Batrachotomus kupferzellensis (Gower \& Schoch, 2009, fig. 2M; SMNS 91046), Gracilisuchus stipanicicorum (Romer, 1972b, fig. 7), and Smilosuchus gregorii (Nesbitt, 2011, fig. 28J).

Dorsal vertebrae. IVPP V6027-1 (Fig. 3A-E) includes what are probably the anteriormost three dorsal vertebrae in articulation, and IVPP V6027-2 (Fig. 3F-J) consists of seven mid- to posterior dorsal vertebrae. The dia- and parapophyses (Fig. 3A,F, di, pa) are close together in the anteriormost vertebra of IVPP V6027-2, indicating that this vertebra is already a mid- or posterior dorsal. In the posteriormost vertebra of IVPP V6027-1, by contrast, the dia- and parapophyses are relatively well separated, and at least the posterior two dorsal vertebrae (what we regard here as the anteriormost dorsal may in fact be the posteriormost) preserved in this specimen can be unequivocally identified as anterior dorsals because they are in articulation with the posteriormost cervicals. Accordingly, IVPP V6027-1 and V6027-2 cannot be combined to form a continuous dorsal series.

414 The anterior dorsal vertebrae are generally similar to the cervical vertebrae described

415 above, but differ in that the diapophyses are longer and dorsoventrally compressed, and are

416 situated higher and further back on the centrum, on the suture with the neural arch. As in most

417 stem and crown archosaurs (e.g. Euparkeria capensis - SAM-PK-5867; Batrachotomus 
418 kupferzellensis - Gower \& Schoch 2009), these differences from the cervical vertebrae become

419 more pronounced posteriorly along the dorsal column. In successively more posterior presacral

420 vertebrae the diapophysis and parapophysis become gradually joined, first being connected by a

421 paradiapophyseal lamina (Fig. 3A, F, ppdl; already present in the more posterior cervical

422 vertebrae) and then fusing entirely to form a single apophysis. The latter condition is present by

423 the fourth preserved vertebra in IVPP V6027-2, although in this vertebra the parapophysis and

424 diapophysis remain distinguishable as components of the apophysis. The diapophysis and

425 parapophysis are indistinguishable from the fifth preserved vertebra of IVPP V6027-2 onwards;

426 this contrasts with Euparkeria capensis, where the apophyses remain distinct units posteriorly in

427 the column (UMZC T.692), and is more similar to the situation in Batrachotomus kupferzellensis

428 (Gower \& Schoch 2009). A low anterior centroparapophyseal lamina (Fig. 3F, acpl) connects the

429 parapophysis (and in more posterior vertebrae, the single fused apophysis) to the anterior margin

430 of the centrum. A thick, rounded prezygadiapophyseal lamina (Fig. 3A,F, prdl) connects the

431 prezygapophysis and the diapophysis. Very similar laminae are seen in Euparkeria capensis

432 (UMZC T.692), but in crown taxa (e.g. Batrachotomus kupferzellensis - Gower \& Schoch 2009)

433 and erythrosuchids (e.g. Erythrosuchus africanus - Gower 2003) the homologous laminae are

434 generally thinner and more sharply delimited.

435 A spinodiapophyseal fossa (Fig. 3F, sdf) is present dorsal to the diapophysis in the third

436 and fifth preserved vertebrae, but the presence of this structure in other vertebrae is difficult to

437 assess due to damage. Very similar fossae are present in Euparkeria capensis (UMZC T.692), but

438 in erythrosuchids (Gower 2003) and crown taxa (Gower \& Schoch 2009) these fossae are more

439 strongly developed. The zygapophyseal facets are very similar to those of the cervical vertebrae,

440 but the plane of articulation between the zygapophyses is more inclined than in the anteriormost

441 two cervical vertebrae (i.e. pre- and postzygapophyseal facets face more strongly medially and

442 laterally respectively). Intercentra (Fig. $3 \mathrm{H}$, ic) are preserved in apparent articulation posterior to

443 the fourth, fifth and sixth vertebrae of IVPP V6027-2; they are mediolaterally elongated ovals in

444 ventral view, and their lateral tips curve dorsally which would have made them crescentic in

445 anterior or posterior view. The intercentra appear to be more robust and larger than those

446 recorded in Euparkeria capensis (Nesbitt 2011), more similar to those of Erythrosuchus

447 africanus (Gower 2003). The dorsal ends of the neural spines (Fig. 3F,G, ns) are expanded into

448 anteroposteriorly elongated oval spine tables that are covered in rugosities. These expansions are

449 somewhat narrower than in Euparkeria capensis (UMZC T.692), being more similar in this

450 regard to those of Jaxtasuchus salomoni (Schoch \& Sues 2013); the rugose surface contrasts with 
451 the flat surface of Euparkeria capensis (UMZC T.692) but does not approach the strongly rugose

452 rim of Jaxtasuchus salomoni (Schoch \& Sues 2013).

453

454 Scapula. IVPP V6027-3 (Fig. 5A-B) is a left scapula in articulation with the coracoid, and IVPP

455 V6027-4 is a right scapula (Fig. 5C-D). The scapula is long and bladelike, and the shaft is

456 waisted at its dorsoventral midpoint in lateral view. This resembles the scapular form in

457 Euparkeria capensis (SAM-PK-5867), erythrosuchids (Gower 2003), proterochampsids (Romer

458 1972a) and cursorial crown taxa (Gower \& Schoch 2009), but contrasts with the low, wide blade

459 of Proterosuchus fergusi (Cruickshank 1972). In posterior view the shaft of the scapula arcs in a

460 medially concave curve. The distal margin of the scapula is damaged in both available scapulae,

461 but is convexly curved in lateral view as preserved, with the apex of curvature closer to the

462 posterior than to the anterior margin. The angle between the distal and posterior margins is

463 slightly under $45^{\circ}$ in the left scapula; the angle in the right scapula is similar, but damage

464 prevents accurate assessment. The angle between the distal and anterior margins is slightly over

$46545^{\circ}$ in the left scapula, and appears similar in the right scapula despite damage to the relevant

466 area. These angles and the form of the distal margin appear to differ from Euparkeria capensis

467 (SAM-PK-5867; where the apex of convexity of the distal margin is roughly central, and both

468 anterior and posterior angles are slightly under $45^{\circ}$ ) and are more similar to Batrachotomus

469 kupferzellensis (Gower \& Schoch 2009). The scapula possesses a pronounced posterolaterally

470 directed tuber placed immediately dorsal to the glenoid along the posterior margin of the bone

471 (Fig. 5A-D, tu; the tuber on the left scapula is damaged). This tuber is for attachment of the

472 scapular head of the $m$. triceps, and has a depressed lateral surface that is circular in outline in

473 lateral view. A similar tuber is present in some "rauisuchians" (e.g. Batrachotomus

474 kupferzellensis - Gower \& Schoch 2009; Nesbitt 2011), but these tubera differ from that of

475 Halazhaisuchus qiaoensis in having an elongated "teardrop" shape rather than a circular one. A

476 distinct tuber is absent in most early archosauriforms (e.g. Euparkeria capensis - SAM-PK-5867,

477 Erythrosuchus africanus - Gower 2003, Smilosuchus gregorii - Nesbitt 2011) and crown taxa,

478 though a muscle scar is often present (Erythrosuchus africanus - NHMUK R3762a).

479 The acromion process (Fig. 5C-F, acr) is larger and more prominent than in Euparkeria

480 capensis (SAM-PK-5867), proterochampsids (Romer 1972a), or Batrachotomus kupferzellensis

481 (Gower \& Schoch 2009), and is not dorsally deflected as it is in erythrosuchids (Gower 2003); its

482 extent is similar to that of Vancleavea campi (Nesbitt 2009), though the process is more dorsally

483 deflected in Vancleavea campi. The lateral surface of the scapula bears a muscle attachment area

484 (Fig. 5A,C, mar) in the form of a parallel ridge and groove. The groove is situated just 
485 anteroventral to the ridge, and both extend posteroventrally from a point on the anterior margin of 486 the scapula that lies about two thirds of the way down from the dorsal end and coincides with the 487 level at which the shaft is anteroposteriorly narrowest. On the medial surface a similarly oriented 488 muscle attachment ridge (Fig. 5B,D, mar) begins on the anterior margin around two thirds of the 489 way up from the ventral end, and terminates at the anteroposteriorly narrowest point of the shaft 490 just anterior to the posterior margin. Neither of these ridges can be identified with certainty in 491 other early archosauriforms (e.g. Erythrosuchus africanus - Gower 2003; Euparkeria capensis 492 SAM-PK-5867, SAM-PK-6047B; Batrachotomus kupferzellensis - Gower \& Schoch 2009;

493 Smilosuchus gregorii - Nesbitt 2011). As in Euparkeria capensis (SAM-PK-6047B), many crown 494 taxa (e.g. Batrachotomus kupferzellensis - Gower \& Schoch 2009; Lewisuchus admixtus 495 Nesbitt 2011), and erythrosuchids (Gower 2003), the posterior part of the shaft is substantially 496 thicker transversely than the anterior part; the shaft is perhaps less strongly tapering in 497 Proterosuchus fergusi (NMQR 1484). As in most early archosauriforms including Euparkeria 498 capensis (SAM-PK-6047B), the proximal end of the shaft is strongly thickened transversely in 499 the glenoid region, which articulates with a similarly thickened part of the coracoid. The coracoid 500 portion of the glenoid appears to be approximately twice as large as the scapular portion, though 501 the latter is damaged posteriorly. The scapula-coracoid suture is gently dorsally convex, with the 502 point of maximum curvature lying around halfway along its length. The suture is clear, though 503 the elements appear to have been firmly attached to one another, contrasting with the freely 504 articulating elements in Euparkeria capensis (SAM-PK-5867), erythrosuchids (Gower 2003), and 505 Batrachotomus kupferzellensis (Gower \& Schoch 2009). Whether or not a distinct anterior notch 506 between the elements was present (contrasting with the continuous margin in Proterosuchus 507 fergusi, non-archosauriform archosauromorphs, and some crown taxa - Nesbitt 2011) cannot be 508 assessed as the anterior margin is broken.

510 Coracoid. IVPP V6027-3 (Fig. 5A-B) includes a left coracoid preserved in articulation with the 511 scapula. As in Euparkeria capensis (SAM-PK-5867, SAM-PK-6047B), erythrosuchids (Gower 512 2003), proterochampsids (Romer 1972a) and "rauisuchians" (Gower \& Schoch 2009), the 513 coracoid is suboval with a single coracoid foramen (Fig. 5A-B, cof) near the dorsal margin, close 514 to the anteroposterior midpoint of the bone. The coracoid is not hooked anteriorly, unlike in 515 phytosaurs (e.g. Smilosuchus gregorii - USNM V18313), nor does it show a postglenoid process

516 (i.e. a notch below the glenoid), unlike in many pseudosuchians (e.g. Batrachotomus

517 kupferzellensis - Gower \& Schoch 2009, Revueltosaurus callenderi-PEFO 34561). As in most 
518 archosauriforms (e.g. Euparkeria capensis - SAM-PK-6047B, Batrachotomus kupferzellensis -

519 Gower \& Schoch 2009, Garjainia prima - PIN 2394), the coracoid becomes mediolaterally

520 thicker towards its contribution to the glenoid (becoming at least five times thicker than at the

521 anteroventral corner, where the bone is thinnest), and also immediately dorsal to the coracoid

522 foramen. The glenoid is orientated posterolaterally, unlike the posteroventral orientation seen in

523 some pseudosuchians and in dinosauromorphs (Nesbitt 2011). The lateral surface of the coracoid

524 immediately ventral to the glenoid is depressed, as in Euparkeria capensis (SAM-PK-6047B) and

525 Batrachotomus kupferzellensis (Gower \& Schoch 2009). With the exception of this area, the

526 lateral surface of the coracoid is smooth, with no sharp ridge from the glenoid to the anteroventral

527 corner, unlike in Prestosuchus (UFRGS 0156-T, Nesbitt 2011).

528

529 Humerus. IVPP V6027-5 (Fig. 6A-F) is a right humerus. In distal view, the angle between the

530 deltopectoral crest and the main shaft is smaller (Fig. 6E, dpc; approximately $50^{\circ}$ ) than in

531 Euparkeria capensis (SAM-PK-5867; approximately $70^{\circ}$ ), with the crest thus protruding

532 ventrally rather than ventrolaterally in Halazhaisuchus qiaoensis. In lateral view (Fig. 6C) the

533 deltopectoral crest projects ventrally as a broad triangular flange and extends distally to

534 approximately the midpoint of the shaft. This is a similar to the distal extent of the crest in

535 Euparkeria capensis (SAM-PK-5867) and Erythrosuchus africanus (Gower 2003), but the crest

536 does not rejoin the shaft distally as abruptly as in the latter taxon. The internal tuberosity (Fig.

537 6D, it) is rounded and not pronounced. As in all archosauriforms (e.g. Euparkeria capensis -

538 SAM-PK-5867, Erythrosuchus africanus - Gower 2003, Batrachotomus kupferzellensis - Gower

$539 \&$ Schoch 2009), the humerus lacks a distinct ossified trochlea (=radial/lateral condyle) and

540 capitellum (=ulnar/medial condyle); in ventral view the distal end is expanded, with a concave

541 distal margin separating distally convex ect- and entepicondyles (Fig. 6D, ect, ent). The rugose

542 and unfinished surface between these epicondyles would probably have borne a strip of cartilage

543 connecting and covering the ect- and entepicondyles as in Caiman (see Romer, 1956, figs. 166-

544 167), and this cartilage might have formed a trochlea and capitellum.

545 The supinator process (Fig. 6B, sup) is a low, rounded ridge extending proximally along

546 the ventrolateral edge of the shaft from the distal end; it is more pronounced than in Euparkeria

547 capensis (SAM-PK-7700), more nearly approaching the level of development in Erythrosuchus

548 africanus (Gower 2003) or Batrachotomus kupferzellensis (Gower \& Schoch 2009). The distal

549 part of the supinator process may have been more prominent in life, but the surface appears to be

550 damaged. Dorsal to the supinator process there is a gently concave strip - this is the

551 ectepicondylar groove (Fig. 6B, ectg), though it is less clearly developed than in Erythrosuchus 
552 africanus (Gower, 2003). It is possible that a more pronounced groove was once present distally,

553 but is now obscured by post-mortem damage. The angle between the long axes of the distal and

554 proximal ends of the humerus is approximately $20^{\circ}$; this is similar to Euparkeria capensis (SAM-

555 PK-5867), but differs from the greater angle ( $\left.>40^{\circ}\right)$ seen in Prolacerta broomi (Gow 1975).

556

557

Ulna. IVPP V6027-6 (Fig. 7A-F) is a right ulna. The olecranon (Fig. 7A-F, ol) is better

558 developed than in Euparkeria capensis (SAM-PK-6047), though not as extensive as in

559 Batrachotomus kupferzellensis (Gower \& Schoch 2009), and is rounded proximally. The

560 proximal surface is convex dorsoventrally. The entire proximal end, including most of the

561 olecranon, has an unfinished surface texture and was seemingly not fully ossified, contrasting

562 with the fully ossified surface in Euparkeria capensis (SAM-PK-6047). The proximal end is

563 suboval in proximal view, tapering dorsally and flattened medially. The shaft is slightly twisted

564 along its length, and has the cross-sectional shape of a dorsoventrally elongated oval with a

565 flattened medial edge. A rounded fossa midway between the dorsal and ventral edges on the

566 medial side of the shaft, near the proximal end, in IVPP V6027-6 (Fig. 7B, fos) may be an

567 artefact of preparation, and is not seen in other early archosauriforms (e.g. Euparkeria capensis -

568 SAM-PK-6047, Batrachotomus kupferzellensis - Gower \& Schoch 2009, Erythrosuchus

569 africanus - Gower 2003).

570 The distal end is convex in lateral or medial view and straight in dorsal and ventral view.

571 In distal view the distal end is a dorsoventrally elongated oval. There is a slightly raised area on

572 the lateral surface at the proximal end of the bone (Fig. 7D-E, ra), although, as in Euparkeria

573 capensis (SAM-PK-6047) and other stem taxa including phytosaurs (Nesbitt 2011), this swelling

574 is too poorly developed to be considered a true radial tuber, contrasting with the prominent tuber

575 present in most crown taxa (Nesbitt 2011; Gower \& Schoch 2009). A ridge (Fig. 7D-E, ri)

576 extends distally along the shaft, beginning approximately $20 \%$ of the way from the proximal end

577 and extending nearly to the distal end. Ventral and parallel to this ridge runs a groove, which

578 becomes narrower distally. Bounding this groove ventrally is a second ridge, less well developed

579 than the first, which angles dorsally as it extends distally. A similar ridge and groove appears to

580 be present in Batrachotomus kupferzellensis (Gower \& Schoch 2009), but not in Erythrosuchus

581 africanus (Gower 2003) and Euparkeria capensis (SAM-PK-5867).

582

583 Radius. IVPP V6027-7 (Fig. 7M-R) is a right radius. The proximal and distal ends of the shaft

584 are formed of unfinished bone (Fig. 7M,O), and their outlines are mediolaterally expanded ovals.

585 The proximal end is expanded slightly further laterally than medially, and the centre of the 
586 proximal surface is depressed, but the proximal margin is straight in dorsal view, contrasting with

587 the slight concave curvature of this margin in Euparkeria capensis (SAM-PK-5867) and the

588 strong concave curvature of this margin in Erythrosuchus africanus (Gower 2003) and

589 Batrachotomus kupferzellensis (Gower \& Schoch 2009). The ventral surface bears a groove that

590 extends along some $80 \%$ of the length of the bone (Fig. 7R, gr), and begins and ends roughly

591 equidistant from each end of the radius. A similar groove appears to be lacking in other early

592 archosauriforms examined (e.g. Euparkeria capensis - SAM-PK-5867, Batrachtomus

593 kupferzellensis - Gower \& Schoch 2009, Erythrosuchus africanus - Gower 2003). The dorsal

594 surface of the radius (Fig. 7Q) is flattened along about $60 \%$ of the length of the shaft, beginning

595 near the proximal end; this flattened area is bordered both medially and laterally by an abrupt

596 break of slope and low ridge. The radial dorsal surface appears to be slightly flattened in those

597 early archosauriforms in which it can be observed (e.g. Erythrosuchus africanus - Gower 2003),

598 but not so as to form a clearly defined strip as seen in Halazhaisuchus qiaoensis. The ventral part

599 of the distal end of the radius is slightly bevelled (Fig. 7R, bev) and rugose. The distal end is

600 convex, as in Euparkeria capensis (SAM-PK-5867), but contrasting with the straighter margin of

601 Batrachotomus kupferzellensis (Gower \& Schoch 2009).

602

603 Median osteoderms. IVPP V6027-1 (Fig.4A-E, Fig.5I) and IVPP V6027-2 (Fig. 3F-J) include

604 median osteoderms in articulation with cervicodorsal and dorsal vertebrae, respectively, and

605 IVPP V6027-8 (Fig. 4E-F) is an isolated median osteoderm. The osteoderms form two parallel

606 rows that contact one another along the midline (Fig. 3B,G). The osteoderms are similar to those

607 of Euparkeria capensis (UMZC T.692; Fig. 4G-H) and many "rauisuchian" pseudosuchians (e.g.

608 Ticinosuchus ferox - Krebs 1965; Rauisuchus tiradentes - Lautenschlager 2008) in each

609 possessing a medially offset longitudinal keel (Fig. 4E,K), being more expanded laterally than

610 medially, in being leaf shaped, and in that each osteoderm dorsally overlaps the immediately

611 more posterior one in the same row. Each osteoderm is around twice as long anteroposteriorly as

612 it is wide mediolaterally. Poorly defined, low rugose striations run out from the keel on the dorsal

613 surface, similar to those seen in Euparkeria capensis (SAM-PK-13666; and not dissimilar to the

614 ornamentation seen in the dorsal osteoderms of Batrachotomus kupferzellensis - Gower \&

615 Schoch 2009), but contrasting markedly with the deep, pitted ornamentation in doswelliids (e.g.

616 Jaxtasuchus - Schoch \& Sues 2013; Desojo et al. 2011), and no anterior smooth lamina for

617 articulation with the preceeding osteoderm is present, contrasting with doswelliids (Desojo et al.

618 2011). 
619 The ventral surface bears rounded rugosities at its edges, which presumably would have 620 articulated with the similar rugosities found on the neural spines below. Similar rugosities appear 621 to be present at the extreme edges of the osteoderms in Euparkeria capensis (Fig. 4H; SAM-PK622 6047A), but are less extensive. The posterior part of the surface directly below the midline keel

623 forms a slight depression with which the osteoderm behind would have articulated, as in

624 Euparkeria capensis (SAM-PK-6047A). Each osteoderm overlaps the neural spines of two

625 vertebrae (Fig. 3B,G), covering the anterior third of the spine of the more posterior vertebra and

626 the posterior two thirds of the spine of the more anterior vertebra. Adjacent left and right

627 osteoderms are level with each other anteroposteriorly rather than staggered; in Euparkeria

628 capensis this seems to vary (SAM-PK-13666; SAM-PK-6048).

629

630

631

632

633

634

635

?EUPARKERIIDAE Huene, 1920 sensu Sookias \& Butler, 2013

'Turfanosuchus shageduensis' Wu, 1982

[Nomen dubium]

636 1), six cervical vertebrae missing upper neural arches and neural spines (V6028-2), right scapula 637 (V6028-3), coracoid (V6028-3), humerus (V6028-4), radius (V6028-7/8/9; note that the correct 638 subnumbers for the radius, ulna and fibula are uncertain), ulna (V6028-7/8/9), femur (V6028-5), 639 tibia (V6028-6) and fibula (V6028-7/8/9). All material probably pertains to a single individual. Horizon and locality. IVPP V6028 is from Jungar Banner, Nei Mongol Autonomous Region,

642 China (Fig. 1), from the lower Ermaying Formation (Lower or Middle Triassic: late Olenekian or 643 early Anisian). Paleobiology Database locality number 92436. See Geological Setting for further 644 information.

645

646 Original diagnosis (paraphrased from Wu, 1982, p. 301). Relatively small pseudosuchian.

647 Narrow and elongated mandible, curving dorsally anteriorly. Narrow scapula, expanded

648 anteriorly distally. Forelimb/hind limb ratio $>0.73$. Humerus robust, ent- and ectepicondyles

649 clearly defined, apex expanded into arc with large deltopectoral crest developed close to proximal

650 end of shaft. Femur strongly sigmoid with large fourth trochanter consisting of triangular ridge.

651 Tibia shorter than femur and more robust. Fibula slender. Vertebrae with slightly elongated

652 centra, lacking intercentra or dorsal scutes.

653

654 Remarks. The holotype, IVPP V6028 is poorly preserved, with extensive preservational damage

655 to the bone surface. This makes identification of details of morphology and thereby potentially 
656 diagnostic features extremely difficult. The original diagnosis of $\mathrm{Wu}$ (1982) was inadequate as

657 none of the characteristics listed are autapomorphic among early archosauriforms, nor is the

658 combination of characters unique. The mandible is described as elongate and narrow, but the

659 ventral and dorsal parts of the ramus are damaged, making comparisons of its dorsoventral depth

660 with other taxa uninformative. The dorsal curvature of the ramus anteriorly is common in

661 archosauriform mandibles (e.g. Euparkeria capensis - SAM-PK-5867, Batrachotomus

662 kupferzellensis - Gower 1999, Erythrosuchus africanus - Gower 2003). The degree of expansion

663 of the scapular blade anteriorly cannot be assessed as the blade is damaged along its anterior

664 margin. The forelimb/hind limb ratio is not unusual among primarily quadrupedal

665 archosauriforms (e.g. 0.67 in Euparkeria capensis - Ewer 1965). The morphology of the humeral

666 condyles and deltopectoral crest is not unusual, being similar to that of Euparkeria capensis

667 (SAM-PK-5867) and Batrachotomus kupferzellensis (Gower \& Schoch 2009). The sigmoid shape 668 and degree of projection of the fourth trochanter of the femur is very similar to that of

669 Euparkeria capensis (SAM-PK-5867) and Dorosuchus neoetus (Sookias et al. in press), and also

670 to proterochampsids (e.g. Chanaresuchus bonapartei-MCZ 4036) and some crown taxa (e.g.

671 Batrachotomus kupferzellensis - Gower \& Schoch 2009). The tibia is neither unusually short nor

672 usually robust (cf. Euparkeria capensis - SAM-PK-6047B, Dorosuchus neoetus - Sookias et al.

673 in press), and similarly slender fibulae are found in other archosauriform taxa (e.g. Gracilisuchus

674 stipanicicorum - PVL 4597). The dimensions of the vertebral centra and the presence or absence

675 of dorsal osteoderms are uncertain as the dorsal portions of the vertebrae are lacking due to

676 damage. Intercentra may have simply not been preserved (the centra are bevelled, indicating they

677 may have been present), or only have been present elsewhere in the column.

678 IVPP V6028 was designated by Wu (1982) as the holotype of a putative new species of

679 the genus Turfanosuchus, 'T. shageduensis'. The type species of Turfanosuchus, Turfanosuchus

680 dabanensis, is from the Kelamayi Formation (Middle Triassic) of Xinjiang, China. Subsequently

681 Gower \& Sennikov (2000) expressed doubts that 'Turfanosuchus shageduensis' and

682 Turfanosuchus dabanensis were congeneric, and noted instead the strong similarities of

683 'Turfanosuchus shageduensis' to Halazhaisuchus qiaoensis from the same formation. However,

684 we find 'Turfanosuchus shageduensis' to be too incomplete and poorly preserved to refer to

685 either of these genera.

686 The most exclusive phylogenetic placement that we find to be unequivocally supported

687 for 'Turfanosuchus shageduensis' is Archosauriformes indet. based on thecodont implantation in 688 the mandible, supporting a placement within Archosauriformes crownward of Proterosuchus 
689 (Nesbitt, 2011). 'Turfanosuchus shageduensis' has a femur that is similar in its sigmoid shape and

690 possession of a symmetrical and rounded fourth trochanter to those of proterochampsids (e.g.

691 Chanaresuchus bonapartei-MCZ 4036), Dorosuchus neoetus (Sookias et al. in press), and some

692 crown archosaurs (e.g. Batrachotomus kupferzellensis - Gower \& Schoch 2009), indicating that

693 it can probably be placed higher on the stem than erythrosuchids (Gower 2003) or Proterosuchus

694 (Nesbitt 2011). We would suggest that tentative assignment to Euparkeriidae is also warranted,

695 based on the lack of a groove on the proximal surface of the femur (contrasting with

696 proterochampsids, e.g. Chanaresuchus bonapartei-MCZ 4036) and apparent weak development

697 of vertebral fossae, unlike the stronger development in crown taxa (e.g. Batrachotomus

698 kupferzellensis - Gower \& Schoch 2009). However, the vertebrae are poorly preserved, and no

699 autapomorphy unites 'Turfanosuchus shageduensis' with Euparkeria capensis or other putative

700 euparkeriids. Whilst the preserved morphology does not preclude the holotype of 'Turfanosuchus

701 shageduensis' from being the same taxon as Halazhaisuchus qiaoensis, and the size and

702 stratigraphic position are broadly comparable, the two share no unambiguous synapomorphies.

703

704 Description

705

706

Mandible. IVPP V6028-1 (Fig. 8; measurements for this and all other elements given in Table S1) is a poorly preserved right mandibular ramus lacking the posteriormost part. Extensive cracking and damage to the external surfaces of most elements prevents accurate identification of sutures. The mandible is ventrally convex in lateral view. The ramus is long anteroposteriorly and shallow dorsoventrally, but the heavily damaged and compressed posterior end of the ramus was probably deeper in life. A mandibular fenestra cannot be identified with certainty due to poor preservation.

712 At least five teeth (Fig. 8, t) and three additional empty alveoli can be identified, and the dentary

713 appears to be long enough to accommodate approximately 12 teeth in total, but the exact

714 posterior extent of the dentary is unclear. This is a similar number to Euparkeria capensis (nine

715 visible and space for at least 11 in SAM-PK-5867), Batrachotomus kupferzellensis (Gower 1999)

716 and Erythrosuchus africanus (approximately 13 - Gower 2003), but fewer than in long-snouted

717 taxa such as Doswellia kaltenbachi (approximately 35 - Dilkes \& Sues 2009) or Chanaresuchus

718 bonapartei (approximately 18 - Romer 1971). The teeth are close to circular in cross-section,

719 seemingly contrasting with the mediolaterally flattened teeth of Euparkeria capensis (SAM-PK-

720 5867), but further details of their morphology cannot be discerned. The prearticular (Fig. 8, pra) 
721 can be identified posteriorly on the medial side, expanding in dorsoventral depth towards its

722 posterior end. The prearticular is mediolaterally thin and dorsoventrally deep with an almost flat

723 (very slightly medially convex in posterior view) and smooth medial surface, as seen in

724 Euparkeria capensis (SAM-PK-5867) or Erythrosuchus africanus (Gower 2003). An abrupt,

725 approximately longitudinal step (Fig. 8, step) demarcates a slightly inset ventral portion of the

726 medial surface of the prearticular that would have been covered by the angular in the intact

727 mandible.

728 Contributing to the anterior portion of the ramus are fragments of bone that, based on 729 their positions, probably represent parts of the splenial (Fig. 8, sp) and coronoid (Fig. 8, c); the

730 portion of the ramus formed by these elements is medially convex in posterior view. The possible

731 coronoid medial to the tooth row is transversely wider in dorsal view than is the part of the

732 dentary lateral to the tooth row. The ventrolateral edge of the dentary (Fig. 8, d) is convex in

733 anterior view, as in most other early archosauriforms (e.g. Euparkeria capensis - SAM-PK-5867,

734 Erythrosuchus africanus - BPI 5207). Ventrally, the dentary and splenial (Fig. 8, sp) are

735 separated by a narrow gap, but this may be due to post-mortem damage, with no such gap present

736 in Euparkeria capensis (SAM-PK-5867). The dorsolateral edge of the area of the mandibular

737 ramus that is likely formed by the surangular (Fig. 8, sa) is convex in anterior view, and was

738 clearly dorsally convex in lateral view when intact. The area of the mandibular ramus that is

739 likely formed by the angular (Fig. 8, a) forms the ventralmost point of the jaw, as in most early

740 archosauriforms (e.g. Euparkeria capensis - SAM-PK-5867, Erythrosuchus africanus - Gower

741 2003, Batrachotomus kupferzellensis - Gower \& Schoch 2009, Proterosuchus fergusi-

742 Cruickshank 1972). The lateral surface of the angular is dorsoventrally convex, and the angular

743 tapers posteriorly in lateral view.

744

745

746

747

748

749

750

751

752

753
Cervical vertebrae. IVPP V6028-2 (Fig. 3K-O) consists of six very poorly preserved, articulated cervical vertebrae, all of which lack the dorsal part of the neural arch including the neural spine. As in Halazhaisuchus qiaoensis and Euparkeria capensis (SAM-PK-5867 - see above), the centra of the cervical vertebrae are spool-shaped and longer than tall as preserved, with low ventral keels. In the anterior of the preserved column the parapophysis (Fig. 3K, pa) is placed anteroventrally and the diapophysis (Fig. 3K, di) is direcly dorsal to it, separated by a narrow gap; this differs from the anteriormost preserved cervical of Halazhaisuchus, where the apophyses are broadly separated, though the difference may in part reflect dorsoventral compression in 'Turfanosuchus shageduensis'. Posteriorly in the column the diapophysis moves 
754 slightly dorsally, but no paradiapophyseal lamina is visible, unlike in Halazhaisuchus qiaoensis.

755 As in Halazhaisuchus qiaoensis (see above), crown taxa and proterochampsids, but contrasting

756 with most stem taxa (Nesbitt 2011), no intercentra can be identified; given that the vertebrae are

757 bevelled, they may have been lost post-mortem as part of the preservation process. The vertebrae

758 of 'Turfanosuchus shagduensis' are slightly longer and lower in their proportions than those of

759 Halazhaisuchus qiaoensis, but this may reflect post-mortem compression of the former given that

760 their ventral surfaces are flattened.

761

762 Scapula. IVPP V6028-3 is a poorly preserved right scapula in articulation with a partial coracoid

763 (Fig. 5E-F). The scapula is broadly similar to that of Halazhaisuchus qiaoensis, with a long,

764 wasted and bladelike shaft, arcing medially. As in Euparkeria capensis (Ewer 1965; SAM-PK-

765 5867) and Halazhaisuchus qiaoensis, the shaft is wider mediolaterally at its posterior margin, and

766 the proximal end is strongly thickened at the glenoid. The margin of the bone is broken in the

767 region in which the tuber for the $m$. triceps would have been placed, but there is a swelling in this

768 position that probably represents what remains of some form of tuber following post-mortem

769 damage (contrasting with Euparkeria capensis, which lacks such a tuber - SAM-PK-5867),

770 though whether it was similar in form to the circular tuber of Halazhaisuchus qiaoensis or the

771 teardrop shaped tubera of "rauisuchians" (e.g. Batrachotomus kupferzellensis - Gower \& Schoch

772 2009; Nesbitt 2011) cannot be ascertained. The muscle attachment ridges identified in

773 Halazhaisuchus qiaoensis are not visible, though they may have been obliterated due to the poor

774 preservation of the surface of the scapula. The scapula has a mediolaterally thinner and slightly

775 anteroposteriorly wider shaft than either scapula of Halazhaisuchus qiaoensis, though this may be

776 in part due to post-mortem mediolateral compression. The scapula and coracoid have broken

777 apart, and damage to their articulating surfaces means that the nature of their articulation is

778 uncertain, though the suture appears to have been roughly horizontal. The scapular contribution

779 to the glenoid is approximately $80 \%$ that of the coracoid.

780

781 Coracoid. IVPP V6028-3 (Fig. 5E-F) includes a partial right coracoid in articulation with the

782 scapula, though the two have broken apart post mortem. The coracoid is broadly similar to that of

783 Halazhaisuchus qiaoensis (see above) in being suboval, thickening towards the glenoid, and

784 showing a lateral depression ventral to the glenoid. A coracoid foramen cannot be identified,

785 though this may be due to preservation. The anterior of the coracoid is lost, and thus whether it

786 was hooked anteriorly (unlike in Halazhaisuchus qiaoensis or Euparkeria capensis - SAM-PK-

787 5867, but as in phytosaurs - e.g. Smilosuchus gregorii, USNM V18313) cannot be ascertained. 
788 As in Halazhaisuchus qiaoensis (and unlike in some pseudosuchians and dinosauromorphs -

789 Nesbitt 2011), the glenoid is orientated posterolaterally. The lateral surface is seemingly smooth,

790 as in Halazhaisuchus qiaoensis, though not well preserved.

791

792 Humerus. IVPP V6028-4 (Fig. 6G-L) is a right humerus, broadly similar in morphology to that

793 of Halazhaisuchus qiaoensis. The deltopectoral crest is broken, but appears to be more laterally

794 directed than in Halazhaisuchus qiaoensis and more similar to that of Batrachotomus

795 kupferzellensis (Gower \& Schoch 2009); this may however be due to mediolateral compression

796 of the entire proximal end of the humerus in Halazhaisuchus qiaoensis, as evidenced by

797 extensive cracks across the surface of the bone. The position of the crest on the humeral shaft

798 does not differ noticeably from that seen in Euparkeria capensis (SAM-PK-5867), contra Wu

799 (1982); like that of Halazhaisuchus qiaoensis, the deltopectoral crest does not rejoin the shaft as

800 abruptly distally as in Erythrosuchus africanus (Gower 2003). The internal tuberosity (Fig. 6 G-

$801 \mathrm{~L}$, it) is visible as a rounded medial projection from near the proximal margin in ventral view.

802 The internal tuberosity is more prominent than that of Halazhaisuchus qiaoensis, and is more

803 similar in extent to that of Euparkeria capensis (SAM-PK-7700; though the tuberosity is not so

804 clearly delimited by a proximal groove/depression in Euparkeria capensis as in 'Turfanosuchus

805 shageduensis'), though this may again partly reflect mediolateral compression of the proximal

806 end in Halazhaisuchus qioaensis. The distal part of the supinator process is damaged, as in

807 Halazhaisuchus qiaoensis.

808

809 Ulna. IVPP V6028 includes a right ulna (Fig. 7G-L) that is either IVPP V6028-7, IVPP 6028-8

810 or IVPP V6028-9 (it is unclear which of these numbers refers to the ulna of IVPP V6028, and

811 which ones to the radius and fibula). The ulna is broadly similar to that of Halazhaisuchus

812 qiaoenis, and details of its morphology are difficult to assess reliably due to extensive damage.

813 However, the olecranon appears to be longer, more tapered, and more dorsally directed than in

814 Halazhaisuchus qiaoensis; the olecranon is similar in extent to that of Batrachotomus

815 kupferzellensis (Gower \& Schoch 2009), but this structure is less rounded in 'Turfanosuchus

816 shageduensis'. The distal end of the ulna also appears to be more expanded dorsally than in

817 Halazhaisuchus qiaoensis, forming a separate lobe proximodorsal to the ventrodistal margin; a

818 similar lobe is seemingly absent in other early archosauriforms (e.g. Batrachotomus

819 kupferzellensis - Gower \& Schoch 2009, Erythrosuchus africanus - Gower 2003), and this

820 feature may be an artefact. No details of the surface of the shaft (ridges, grooves) are discernible 
821 due to preservation. No proximal fossa on the medial surface similar to that of Halazhaisuchus

822 qiaoensis (which may be an artefact - see above) is visible.

823

824 Radius. IVPP V6028 includes a poorly preserved right radius (Fig. 7S-X; either IVPP V6028-7,

825 IVPP V6028-8, or IVPP V6028-9, see above). The radius is generally similar to that of

826 Halazhaisuchus qiaoensis. Like in the ulna, extensive damage prevents details of morphology

827 such as ridges and grooves from being discerned. The radius appears to be slightly more slender

828 than that of Halazhaisuchus qiaoensis, especially distally, and to lack any lateral expansion

829 proximally (unlike in Halazhaisuchus qiaoensis where the proximal end is equally expanded

830 laterally and medially), though the latter feature may be due to preservation as this does not occur

831 in other early archosauriforms (e.g. Batrachotomus kupferzellensis - Gower \& Schoch 2009,

832 Erythrosuchus africanus - Gower 2003).

833

834 Femur. IVPP V6028-5 (Fig. 9) is a right femur. The shaft is sigmoidal, as in Euparkeria capensis

835 (SAM-PK-5867), proterochampsids (Romer 1972a), and many crown taxa (Gower \& Schoch

836 2009), but contrasting with the straighter shaft of erythrosuchids (Gower 2003) and

837 proterosuchids (Cruickshank 1972). In distal view, the angle of offset between the long axes of

838 the distal and proximal ends $\left(40-50^{\circ}\right)$ is similar to the corresponding angle in Euparkeria

839 capensis (SAM-PK-6047B), but contrasts strongly with the $60^{\circ}-90^{\circ}$ deflection seen in

840 Vancleavea campi (Nesbitt 2009) and phytosaurs (Nesbitt 2011) and with the $<20^{\circ}$ deflection in

841 Jaxtasuchus salomoni (Schoch \& Sues 2013). The proximal end of the femur is a dorsomedially-

842 ventrolaterally elongated oval in proximal view (Fig. 9B); the bone surface is rugose and very

843 slightly concave, indicating the presence of a cartilaginous proximal end in life, but is not

844 pronouncedly depressed as in erythrosuchids (Gower 2003) and proterochampsids

845 (Chanaresuchus bonapartei - PVL 6244). A low ridge (=medial tuber of Nesbitt, 2011) extends

846 distally along the ventral surface of the femur, beginning at the proximal margin then nearly

847 merging indistinguishably with the bone surface, before redeveloping into a clear fourth

848 trochanter (Fig. 9D-F, 4t). As in Euparkeria capensis (SAM-PK-5883, SAM-PK-6047B) and

849 most non-crown taxa (e.g. Chanaresuchus bonapartei - MCZ 4035, Dorosuchus neoetus -

850 Sookias et al. in press, phytosaurs - Nesbitt 2011) there is thus only a single medial tuber, rather

851 than an anteromedial and posteromedial tuber. As in Euparkeria capensis (SAM-PK-5883, SAM-

852 PK-6047B), proterochampids (Romer 1972a) and crown taxa (Gower \& Schoch 2009), the fourth

853 trochanter forms a laterally convex arc in ventral view. The apex of the trochanter is halfway

854 between the proximal and distal ends of this structure and situated closer to the medial margin of 
855 the femur than to the lateral margin; the trochanter is mediolaterally widest at this point. The 856 presence of a symmetrical fourth trochanter contrasts with the large, blade-like, asymmetric 857 attachment ridge for the $m$. caudifemoralis seen in erythrosuchids (Gower 2003), proterosuchids

858 (Cruickshank 1972), and non-archosauriform archosauromorphs (e.g. Trilophosaurus buettneri-

859 Spielmann et al. 2008), and is far more similar to taxa just outside the crown including

860 Euparkeria capensis (SAM-PK-5883, SAM-PK-6047B), Dorosuchus neoetus (Sookias et al. in

861 press) and proterochampsids (Romer 1972a), and to crown taxa (e.g. Batrachotomus

862 kupferzellensis - Gower \& Schoch 2009).

863 A raised ring of bone surrounding a rugose depression lateral to the proximal end of the 864 trochanter (Fig. 9E, cfb) may, following the arrangement in Alligator (Romer, 1923; Hutchinson, 865 2001b; Schachner, Manning \& Dodson, 2011), be the area of insertion for the $m$. caudofemoralis

866 brevis, and the trochanter itself in addition to a proximomedially adjacent rugose area (Fig. 9E,

867 cfl) may represent the area of insertion for the m. caudofemoralis longus (again following 868 Alligator - Romer, 1923; Hutchinson, 2001b; Schachner, Manning \& Dodson, 2011). Similar 869 areas of probable muscle scarring are visible in Euparkeria capensis (SAM-PK-5883), though 870 they are not readily identifiable even in some taxa otherwise similar in femoral morphology (e.g.

871 Batrachotomus kupferzellensis - Gower \& Schoch 2009). A rounded and raised area on the lateral

872 surface of the femur (Fig. 9B, fte), about one third of the shaft length from the proximal end, may 873 mark the proximal part of the area of origin of the m. femorotibialis externus (as identified in 874 Alligator - Romer, 1923; Hutchinson, 2001b; Schachner, Manning \& Dodson, 2011). This raised 875 area is adjacent to a slight bulge on the ventrolateral margin of the femur, referred to here as the 876 ventral eminence (Fig. 9B, ve). Whilst the ventral eminence is clearly present in Euparkeria 877 capensis (SAM-PK-5883, SAM-PK-6047B) and Erythrosuchus africanus (Gower 2003), the $m$.

878 femorotibialis externus area is not readily identifiable in these taxa.

879 The shaft has an egg-shaped cross-section, in that the ventral margin of the shaft is

880 narrower mediolaterally than the dorsal margin and narrows further to form the adductor crest 881 (Fig. 9D, ac) as it passes distally. The distal end of the femur is divided into lateral and medial 882 condyles (Fig. 9E, lc, mc) that are separated by an intercondylar groove distally (Fig. 9F, ig) and 883 dorsally, and by a shallowly depressed popliteal space ventrally (Fig.9D, ps). This arrangement is 884 similar to that in Euparkeria capensis (SAM-PK-5883, SAM-PK-6047B), though the condyles 885 are less strongly defined in the latter taxon, and is also found in crown taxa (Gower \& Schoch 886 2009), proterochampsids (Romer 1972a), doswelliids (Schoch \& Sues 2013), and Dorosuchus 887 neoetus (Sookias et al. in press). In erythrosuchids, the condyles are much less strongly defined, 
888 though they project further beyond the midshaft width (Gower 2003). The lateral condyle bears a

889 tapered, ventrally projecting crista tibiofibularis (Fig. 9C, ct); damage to the lateral margin of the

890 condyle and crista tibiofibularis impedes assessment of whether the angle between the two was

891 obtuse (as in Euparkeria capensis and most stem and avian-line archosaurs) or close to a right

892 angle (as in some crown pseudosuchians including Batrachotomus kupferzellensis) (see Nesbitt

893 2011). The bone surface of the distal end (Fig. 9F) is rugose, indicating a large cartilaginous

894 epiphysis in life.

895

896 Tibia. IVPP V6028-6 (Fig. 10A-F) is a right tibia. The proximal end of the tibia is around twice

897 as expanded dorsoventrally (23 mm versus $13.2 \mathrm{~mm}$ as preserved) and mediolaterally (21.5 mm

898 versus $14.7 \mathrm{~mm}$ as preserved) as the distal end; this is greater than the degree of expansion seen

899 in Euparkeria capensis (SAM-PK-5867) or Batrachotomus kupferzellensis (Gower \& Schoch

900 2009), and is more similar to the expansion seen in proterochampsids (Romer 1972a),

901 erythrosuchids (Garjainia prima - PIN 951/28), and Dorosuchus neoetus (Sookias et al. in press,

902 though the expansion is less symmetrical in this taxon). The proximal end has relatively straight

903 dorsomedial, dorsolateral and ventrolateral edges and a convexly curved ventromedial edge in

904 proximal view (Fig. 10A). The dorsal margin of the proximal end is expanded to form a small

905 cnemial crest (Fig. 10A,B, cn), similar to the small bump in Euparkeria capensis (SAM-PK-

906 5867) and contrasting with the more pronounced crest of dinosauromorphs (Nesbitt 2011). The

907 ventrolateral corner of the proximal end is very slightly expanded to form an indistinct posterior

908 condyle (Fig. 10A, pc), as in Euparkeria capensis (SAM-PK-5867).

$909 \quad$ As in most early archosauriforms (but contrasting with theropods - Nesbitt 2011), the

910 proximal surface of the tibia is convex overall; however, it is interrupted by a dorsoventrally

911 elongated concavity that is closer to the lateral margin of the proximal surface than the medial

912 margin. The shaft of the tibia displays a dorsally convex curvature in lateral view (Fig. 10D),

913 contrasting with the equally dorsally and ventrally concave shaft of Euparkeria capensis (SAM-

914 PK-5867) and more similar to the shape in Dorosuchus neoetus (Sookias et al. in press). The

915 cross-sectional shape of the shaft is a mediolaterally compressed ellipse, less close to circular

916 than in Euparkeria capensis (SAM-PK-6047B) and more similar to Dorosuchus neoetus (Sookias

917 et al. in press), though this may in part be due to damage. As preserved, the distal end of the tibia

918 has the outline of an oval elongated along a ventrolateral-to-dorsomedial axis (Fig. 10C), and is

919 very slightly concave. This differs markedly from the almost circular distal end in Euparkeria

920 capensis (SAM-PK-6047B), and the elliptical but less strongly elongated one in Dorosuchus

921 neoetus (Sookias et al. in press), though this may again in part be due to post mortem damage. No 
922 definite attachment site for the $m$. puboischiotibialis can be identified (unlike the condition in

923 Erythrosuchus africanus, Gower 2003). There is a step (Fig. 10F, step) on the medial surface of

924 the tibia, beginning around one quarter of the way down the shaft. This step separates the more

925 prominent ventral part of the medial surface of the tibia from the more subdued dorsal part. No

926 similar feature can be identified in other early archosauriforms (e.g. Euparkeria capensis - SAM-

927 PK-6047B, Dorosuchus neoetus - Sookias et al. in press, Erythrosuchus africanus - Gower

928 2003), and it may be a preservational artefact.

929

930 Fibula. IVPP V6028 includes a right fibula (Fig. 10G-L; either IVPP V6028-7, IVPP V6028-8,

931 or IVPP V6028-9, see above). The fibula is long and slender (ratio of shaft diameter to shaft

932 length is lower than in Euparkeria capensis - SAM-PK-5867 - and more similar to Gracilisuchus

933 stipanicicorum - Lecuona \& Desojo 2011), relatively straight (showing some curvature, as in

934 Euparkeria capensis - SAM-PK-5867 and Gracilisuchus stipanicicorum - Lecuona \& Desojo

935 2011), but contrasting with the curved fibula of, e.g., Postosuchus kirkpatricki - TTU-P 9002,

936 and the straight element of dinosauromorphs - Nesbitt 2011) and flattened mediolaterally. The

937 proximal end of the fibula is missing, but the proximalmost preserved part of the bone bears an

938 eminence on the lateral surface (Fig. 10J, m.if) that was interpreted by $\mathrm{Wu}$ (1982) as the insertion

939 site for the $m$. iliofibularis (corresponding to the anterior trochanter of e.g. Borsuk-Białynicka \&

940 Sennikov, 2009). This interpretation is plausible, but the attachment would then be more

941 proximally positioned than in most stem and early archosaurs (e.g., Nesbitt, 2011: fig. 41). A

942 possible exception is Osmolskina (Borsuk-Białynicka \& Sennikov, 2009), but no fibula has been

943 assigned to this taxon with more than tentative certainty. However, a proximally placed $m$.

944 iliofibularis insertion is characteristic of derived pseudosuchians (e.g. Crocodylus niloticus:

945 Borsuk-Białynicka \& Sennikov, 2009).

$946 \quad$ The shaft tapers mediolaterally and dorsoventrally for more than half of its preserved

947 length before reexpanding distally. The long axes of the distal part of the shaft and the

948 proximalmost preserved part are offset by around $75^{\circ}$. The shaft is oval in cross-section, but the

949 dorsal surface is pinched to form an elongated ridge (Fig. 10G, ri). The distal end of the shaft is

950 strongly expanded ventrolaterally to dorsomedially, and the ventrolateral margin of the distal end

951 is much wider in distal view than the dorsomedial margin. Euparkeria capensis (SAM-PK-5867)

952 lacks such a strong ventrolateral-dorsomedial expansion but some degree of expansion is seen in

953 most early archosauriforms (e.g. Postosuchus kirkpatricki-TTU-P 9002, Proterosuchus fergusi-

954 NM QR 880). A small groove (Fig. 10K, ?gr) runs proximodistally along the ventral surface of

955 the fibula near the distal end, though this may be an artefact of poor preservation as it is not 
956 shared with other taxa (e.g. Postosuchus kirkpatricki-TTU-P 9002, Proterosuchus fergusi - NM

957 QR 880, Batrachotomus kupferzellensis - Gower \& Schoch 2009). In lateral view, the distal

958 margin of the fibula is embayed between dorsal and ventral rounded convexities, and the ventral

959 end of the distal margin is more proximal than the dorsal end, probably in order to form an

960 articulation for the astragalus, as seen in many pseudosuchians (e.g. Postosuchus kirkpatricki-

961 TTU-P 9002, Hesperosuchus agilis - AMNH FR 6758), but unlike in Euparkeria capensis

962 (SAM-PK-5867) or Proterosuchus fergusi (NM QR 880). The lateral surface of the distal end is

963 depressed at its dorsoventral midpoint.

964

965

966

967

968

969

Phylogenetic relationships of Halazhaisuchus qiaoensis and

\section{'Turfanosuchus shageduensis'}

Although we find 'Turfanosuchus shageduensis' to be a nomen dubium due to lack of diagnostic characters, we placed both it and Halazhaisuchus qiaoensis in a phylogenetic analysis, as both taxa could be scored for a reasonable number of characters. Our initial phylogenetic analysis (Fig. 11) including Halazhaisuchus qiaoensis and 'Turfanosuchus shageduensis' yielded 810 most parsimonious trees (MPTs) of 1257 steps with a consistency index (CI) of 0.384 and a retention index (RI) of 0.793. Halazhaisuchus qiaoensis and 'Turfanosuchus shageduensis' were

974 found to be sister taxa, forming a clade that was in turn placed as sister to Euparkeria capensis.

975 This result is consistent with the general similarity of 'Turfanosuchus shageduensis' to

976 Halazhaisuchus qiaoensis, but the taxa are not united by any autapomorphies. The result supports

977 a monophyletic Euparkeriidae, consisting of Euparkeria capensis, Halazhaisuchus qiaoensis, and

978 potentially 'Turfanosuchus shageduensis', that forms the sister clade to Archosauria+Phytosauria.

979 However, this Euparkeriidae is supported only by one local apomorphy - character 407, presacral

980 osteoderms that are longer than wide - and osteoderms are not preserved in 'Turfanosuchus

981 shageduensis'. The sister grouping of Halazhaisuchus qiaoensis and 'Turfanosuchus

982 shageduensis' is supported by a single local apomorphy: 219, teardrop-shaped tuber on posterior

983 edge of scapula present (following the wording of Nesbitt, 2011 - the tuber of Halazhaisuchus

984 qiaoensis is in fact circular, but is almost certainly homologous with the teardrop shaped tubera

985 of other taxa). Bootstrap support for the node Euparkeriidae+(Archosauria+Phytosauria) is $60 \%$,

986 with a Bremer support of three, but bootstrap support for Euparkeriidae and for Halazhaisuchus

987 qiaoensis+'Turfanosuchus shageduensis' is $<40 \%$ and Bremer support for both nodes is one.

988 Seven extra steps were required to find a monophyletic clade composed of 'Turfanosuchus 
989 shageduensis', Halazhaisuchus qiaoensis and Turfanosuchus dabanensis (whether or not

990 'Turfanosuchus shageduensis' and Halazhaisuchus qiaoensis were constrained to be sister taxa).

991 Turfanosuchus dabanensis was placed as the sister taxon of Gracilisuchus + Yonghesuchus within

992 Pseudosuchia, as found by Butler et al. (2014). Nineteen extra steps were required to recover a

993 monophyletic Euparkeriidae composed of a combined Halazhaisuchus qiaoensis, 'Turfanosuchus

994 shageduensis', Turfanosuchus dabanensis and Euparkeria capensis (whether or not

995 'Turfanosuchus shageduensis' and Halazhaisuchus qiaoensis were constrained to be sister taxa).

996 One extra step was required to place a 'Turfanosuchus shageduensis' and Halazhaisuchus

997 qiaoensis clade one node outside Euparkeria+(Phytosauria+Archosauria), or to place such a

998 clade one node above Euparkeria as the sister taxon to Phytosauria+Archosauria.

999 As the possibility cannot be excluded that 'Turfanosuchus shageduensis' represents a

1000 second specimen of Halazhaisuchus qiaoensis, we also conducted analyses with the taxa treated

1001 as a single operational taxonomic unit (OTU). The recovered tree topology (excepting of course

1002 the sister group relationship of the two taxa in question) and character optimizations were

1003 identical to those found in the previous analysis when Halazhaisuchus qiaoensis and

1004 'Turfanosuchus shageduensis' were combined as a single taxon, and support values differed only

1005 slightly (Bremer support of four for Archosauria+Phytosauria). This analysis recovered 270

1006 MPTs of 1276 steps with a CI of 0.379 and an RI of 0.787. Turfanosuchus dabanensis was placed

1007 as the sister taxon of Gracilisuchus+Yonghesuchus within Pseudosuchia, as found by Butler et al.

1008 (2014). Seven extra steps were required to place Turfanosuchus dabanensis as the sister taxon to

1009 the combined Halazhaisuchus qiaoensis. Nineteen extra steps were required to recover a

1010 monophyletic Euparkeriidae composed of a combined Halazhaisuchus qiaoensis OTU,

1011 Turfanosuchus dabanensis and Euparkeria capensis.

1012

1013 Discussion

1014

1015 We consider 'Wangisuchus tzeyii' to be a nomen dubium due to the undiagnostic nature of the

1016 holotype material. Whilst some of the material currently assigned to the taxon may indeed pertain

1017 to a euparkeriid or euparkeriid-grade species, the specimens are too fragmentary and poorly

1018 preserved for a reasonable assessment of their systematic position to be made. The problem is

1019 compounded by the lack of convincing evidence that any of the different specimens pertain to the

1020 same individual or taxon, especially given that other archosauromorphs (e.g. Shansisuchus

1021 shansisuchus) were collected from the same localities and strata. 
Although Halazhaisuchus qiaoensis and the holotype of 'Turfanosuchus shageduensis'

1023 were found to be sister taxa, and there are no major differences in morphology between

1024 overlapping elements of the two taxa, we feel the morphology of 'Turfanosuchus shageduensis' is

1025 not well enough preserved to allow synonymization of the taxa. The diagnostic characters of

1026 Halazhaisuchus qiaoensis are not preserved (and may not have been present) in 'Turfanosuchus

1027 shageduensis', and we regard 'Turfanosuchus shageduensis' as only diagnosable as an

1028 indeterminate archosauriform, and possibly a euparkeriid. 'Turfanosuchus shageduensis' shares

1029 all characters for which it could be scored with Euparkeria capensis and Halazhaisuchus

1030 qiaoensis, except for the presence on the scapula of a tuber for the $m$. triceps, which it only shares

1031 with the latter. Thus tentative placement of 'Turfanosuchus shageduensis'as a euparkeriid appears

1032 reasonable, but the only potential euparkeriid autapomorphy identified here - osteoderm shape -

1033 is not preserved in the taxon. Even if 'Turfanosuchus shageduensis' is not a euparkeriid, it can be

1034 safely concluded that it is a stem archosaur of a similar grade to Euparkeria capensis and

1035 Halazhaisuchus qiaoensis.

$1036 \quad$ Our phylogenetic analysis constitutes only the third test of the existence of a

1037 monophyletic, non-monospecific Euparkeriidae, the first being an analysis by Ezcurra, Lecuona

1038 \& Martinelli (2010) that included the putative euparkeriids Osmolskina czatkowicensis and

1039 Euparkeria capensis, and the second being an analysis by Sookias et al. (in press) that included

1040 the putative euparkeriids Dorosuchus neoetus and Euparkeria capensis. As neither of these

1041 previous studies found the putative euparkeriids included in the analysis to be sister taxa, our

1042 analysis is the first to recover a monophyletic, non-monospecific euparkeriid clade. Our ongoing

1043 work is focused on developing a more extensive dataset to simultaneously test the positions of

1044 Euparkeria capensis, Dorosuchus neoetus, Halazhaisuchus qiaoensis, and Osmolskina

1045 czatkowicensis, but this is beyond the scope of the current paper.

1046 Although Halazhaisuchus qiaoensis, 'Turfanosuchus shageduensis' and Euparkeria

1047 capensis form a clade in our analysis, this result must be considered provisional as only three of

1048 the putative euparkeriid taxa were included in the analysis and support for the clade was low,

1049 with osteoderm shape constituting the only synapomorphy of the clade (with osteoderms not

1050 preserved in 'Turfanosuchus shageduensis'). The osteoderms of Halazhaisuchus qiaoensis and

1051 Euparkeria capensis are indeed very similar, being leaf-shaped and possessing medially offset

1052 longitudinal keels. Moreover, the osteoderms are arranged almost identically in the two taxa,

1053 forming in each case two paramedian rows slightly out of step with the spine tables below them.

1054 However, very similar osteoderms are found in several crown pseudosuchians (e.g. Ticinosuchus 
1055 ferox - Krebs 1965; Rauisuchus tiradentes - Lautenschlager 2008), and doswelliids (e.g.

1056 Jaxtasuchus - Schoch \& Sues 2013) show some osteoderms longer than wide, though not of the

1057 same shape as those of Halazhaisuchus qiaoensis. Unlike the condition in doswelliids (Desojo et

1058 al. 2011), no characteristics of the osteoderms appear to be unique to Euparkeriidae. Euparkeria

1059 capensis also differs from Halazhaisuchus qiaoensis in lacking the pronounced scapular tuber for

1060 muscle attachment that is an apparent autapomorphy of the latter taxon, and in more subtle

1061 aspects of shape in several elements (e.g. Euparkeria capensis has a less well developed

1062 olecranon process of the ulna, and a slightly less strongly expanded distal end of the scapula). It

1063 should also be noted that our scoring for osteoderm shape differs from that of Nesbitt (2011:

1064 character 407), who scored the osteoderms of Euparkeria capensis as "square-shaped, about

1065 equal dimensions" rather than "longer than wide". We disagree with this scoring as the maximum

1066 width to maximum length ratio of the paramedian osteoderms of Euparkeria capensis is 0.43

1067 (UMZC T.692j). This is similar to the value for Batrachotomus kupferzellensis (0.46, SMNS

1068 90018), which Nesbitt (2011) scored as having elongated osteoderms, but strikingly different

1069 from that for Hesperosuchus agilis (0.72, AMNH FR 6758, measured from fig. 50 in Nesbitt,

1070 2011) which Nesbitt (2011) scored as having square-shaped osteoderms. The width to length ratio

1071 is 0.47 in Halazhaisuchus qiaoensis (IVPP V6027-8), again more similar to the condition in

1072 Batrachotomus kupferzellensis than that in Hesperosuchus agilis.

1073 Although 'Turfanosuchus shageduensis' is not diagnosable, some ecological inferences

1074 can be drawn from the specimen based on tooth shape and forelimb/hind limb ratios. The animal

1075 can be estimated to have been around $1.5 \mathrm{~m}$ in length, based on length estimates for Euparkeria

1076 capensis (Ewer, 1965; Remes, 2007; Botha-Brink \& Smith, 2011) scaled according to the length

1077 ratio between its femur $(127 \mathrm{~mm})$ and the longest femur of Euparkeria capensis (78 mm, SAM-

1078 PK-10671). 'Turfanosuchus shageduensis' was also probably carnivorous, based on the

1079 apparently cylindrical shape of the preserved teeth, though no details of dental morphology can

1080 be discerned. Locomotor ability similar to that posited for Euparkeria capensis, namely

1081 quadrupedal locomotion and possibly facultative bipedality at speed (Ewer, 1965; Santi, 1993),

1082 can be tentatively ascribed to 'Turfanosuchus shageduensis': the humerus/femur ratio (1.51 for

1083 IVPP V6028), femoral length as percentage of femur+tibia length (55\% for IVPP V6028), and

1084 humerus+ulna length as a percentage of femur+tibia length (69\% for IVPP V6028) are similar to

1085 the corresponding values for Euparkeria capensis (1.40, approximately 63\%, and 67\%,

1086 respectively; Ewer, 1965, Gauthier et al., 2011). Femoral morphology is also similar, though the

1087 tibia is less symmetrical mediolaterally than that of Euparkeria capensis. Lack of preservation of 
1088 the pelvic girdle precludes further conclusions regarding locomotor ability. Halazhaisuchus

1089 qiaoensis does not possess hind limb material or teeth, precluding similar inferences, although the

1090 forelimb elements and pectoral girdle are very similar in shape to those of 'Turfanosuchus

1091 shageduensis'. The double row of paramedian osteoderms possessed by Halazhaisuchus

1092 qiaoensis may have assisted in locomotion, as has been posited for Euparkeria capensis (Ewer

1093 1965), and the osteoderms present certainly do not seem extensive enough to have provided

1094 significant protection.

1095 Our reassessment of the putative Chinese Euparkeriidae helps to shed light on character

1096 evolution leading up to the origin of archosaurs. Together with Euparkeria capensis, the

1097 morphology of 'Turfanosuchus shageduensis' and of Halazhaisuchus qiaoensis probably

1098 approaches that of the common ancestor of Phytosauria+Archosauria. Whilst the locomotor

1099 apparatus of Euparkeria capensis and 'Turfanosuchus shageduensis' is not specialized for fully

1100 upright or bipedal locomotion, unlike that of early dinosauriforms and pseudosuchians (see

1101 Gauthier et al., 2011), it departs from that of more sprawling taxa, with reduction and ventral

1102 displacement of the fourth trochanter. Based on Halazhaisuchus qiaoensis, 'Turfanosuchus

1103 shageduensis' and Euparkeria capensis, the ancestor of Archosauria and phytosaurs can also be

1104 hypothesised to have been relatively small and gracile, terrestrial, and probably carnivorous. The

1105 vertebrae of Halazhaisuchus qiaoensis show some structures that correspond to the extensive

1106 laminae and fossae of Archosauria, phytosaurs, and some other non-archosaurian archosauriforms

1107 (e.g. erythrosuchids - Gower 2003; Cuyosuchus - Desojo, Arcucci \& Marsicano 2002). Such

1108 features have often, but controversially, been considered to indicate the presence of pneumatic

1109 diverticula (see Butler, Barrett \& Gower, 2012), but in Halazhaisuchus qiaoensis these structures

1110 are not particularly well developed. Halazhaisuchus qiaoensis, along with Euparkeria capensis,

1111 is intermediate in development of vertebral laminae and fossae between the archosaurs and

1112 phytosaurs on the one hand and more basal taxa such as Proterosuchus fergusi on the other.

1113 However, laminae and fossae are better developed in Erythrosuchus africanus than in

1114 Euparkeriidae (Gower, 2003; Butler, Barrett \& Gower, 2012) despite the more crownward

1115 placement of the latter, implying that the elaboration of laminae and fossae in archosauriform

1116 evolution (whether related to pneumaticity or not) did not follow a simple trend.

1117

1118 Acknowledgements

1119 
1120 The authors thank A. B. Heckert, J. B. Desojo and an anonymous reviewer for their comments

1121 and suggestions, which greatly improved the quality of the manuscript. The authors also thank K.

1122 Tang (University College London) for assistance with Chinese language names.

1123

\section{Funding}

1125

1126 R.B.S. and R.J.B. are supported by an Emmy Noether Programme Award from the Deutschen

1127 Forschungsgemeinschaft (BU 2587/3-1 to R.J.B.) and by a Marie Curie Career Integration Grant

1128 (PCIG14-GA-2013-630123 ARCHOSAUR RISE to R.J.B.). C.S. and L.J. are supported by the

1129 Institute of Vertebrate Paleontology and Paleoanthropology of the Chinese Academy of Sciences,

1130 Beijing.

1131

1132

1133

1134

1135

1136

1137

1138

1139

1140

1141

1142

1143

1144

1145

1146

1147

1148

1149

1150

1151

1152

1153

1154

1155

1156

1157

1158

1159

\section{References}

Bennett SC. 1996. The phylogenetic position of the Pterosauria within the Archosauromorpha.

Zoological Journal of the Linnean Society 118:261-308.

Benton MJ. 1999. Scleromochlus taylori and the origin of the dinosaurs and pterosaurs.

Philosophical Transactions of the Royal Society of London B 354:1423-1446.

Benton MJ, Donoghue PCJ. 2007. Paleontological evidence to date the tree of life. Molecular

Biology and Evolution 24:26-53.

Borsuk-Białynicka M, Evans SE. 2003. A basal archosauriform from the Early Triassic of Poland. Acta Palaeontologica Polonica 48:649-653.

Borsuk-Białynicka M, Sennikov AG. 2009. Archosauriform postcranial remains from the Early

Triassic karst deposits of southern Poland. Palaeontologia Polonica 65:283-328.

Borsuk-Białynicka M, Evans SE. 2009. Cranial and mandibular osteology of the Early Triassic archosauriform Osmolskina czatkowicensis from Poland. Palaeontologica Polonica 65:235-281.

Botha-Brink J, Smith RMH. 2011. Osteohistology of the Triassic archosauromorphs Prolacerta, Proterosuchus, Euparkeria, and Erythrosuchus from the Karoo Basin of South Africa. Journal of Vertebrate Paleontology 31:1238-1254.

Brusatte SL, Benton MJ, Desojo JB, Langer MC. 2010. The higher-level phylogeny of the Archosauria (Tetrapoda: Diapsida). Journal of Systematic Palaeontology 8:3-47.

Butler RJ, Brusatte S L, Reich M, Nesbitt SJ, Schoch RR, Hornung JJ. 2011. The sail-backed 
1160 reptile Ctenosauriscus from the latest Early Triassic of Germany and the timing and

1161 biogeography of the early archosaur radiation. PLOS ONE 6: e25693.

1163 Butler RJ, Barrett PM, Gower DJ. 2012. Reassessment of the evidence for postcranial skeletal

1164 pneumaticity in Triassic archosaurs, and the early evolution of the avian respiratory system. PLoS

1165 ONE 7: e34094.

1167 Butler RJ, Sullivan C, Ezcurra MD, Liu J, Lecuona A, Sookias RB. 2014. New clade of enigmatic

1168 early archosaurs yields insights into early pseudosuchian phylogeny and the biogeography of the

1169 archosaur radiation. BMC Evolutionary Biology 14:128.

Carrier DR, Farmer CG. 2000. The evolution of pelvic aspiration in archosaurs. Paleobiology

1172 26:271-293.

Cohen KM, Finney S, Gibbard PL. 2013. International Chronostratigraphic Chart 2013/01. International Commission on Stratigraphy.

Cruickshank ARI. 1972. The proterosuchian thecodonts. In: Joysey KA, Kemp TS, eds. Studies in vertebrate evolution. Edinburgh: Oliver \& Boyd, 89-119.

Desojo JB., Arcucci AB, Marsicano CA. 2002. Reassessment of Cuyosuchus huenei, a MiddleHistory and Science Bulletin 21. Albuquerque: New Mexico Museum of Natural History and Science, $143-148$.

Desojo JB, Ezcurra MD, Schultz CL. 2011. An unusual new archosauriform from the MiddleLate Triassic of southern Brazil and the monophyly of Doswelliidae. Zoological Journal of the

Dilkes, D., Sues, H. D. 2009. Redescription and phylogenetic relationships of Doswellia

Domnanovich NS, Marsicano CA. 2012. The Triassic dicynodont Vinceria (Therapsida, Anomodontia) from Argentina and a discussion on basal Kannemeyeriiformes. Geobios 45: 173186.

Ewer RF. 1965.The anatomy of the thecodont reptile Euparkeria capensis Broom. Philosophical 
1199

1200

1201

1202

1203

1204

1205

1206

1207

1208

1209

1210

1211

1212

1213

1214

1215

1216

1217

1218

1219

1220

1221

1222

1223

1224

1225

1226

1227

1228

1229

1230

1231

1232

1233

1234

1235

1236

1237

1238

1239

Transactions of the Royal Society of London B 248:379-435.

Ezcurra MD, Lecuona A, Martinelli A. 2010. A new basal archosauriform diapsid from the Lower Triassic of Argentina. Journal of Vertebrate Paleontology 30:1433-1450.

Ezcurra MD, Scheyer T, Butler RJ. 2014. The origin and early evolution of Sauria: reassessing the Permian saurian fossil record and the timing of the crocodile-lizard divergence. PLoS ONE 9: e89165.

Foth C, Rauhut OWM. 2013. Macroevolutionary and morphofunctional patterns in theropod skulls: a morphometric approach. Acta Palaeontologica Polonica 58:1-16.

Fröbisch J. 2009. Composition and similarity of global anomodont-bearing tetrapod faunas. Earth-Science Reviews 95:119-157.

Gauthier JA, Kluge AG, Rowe T. 1988. Amniote phylogeny and the importance of fossils. Cladistics 4:105-209.

Gauthier JA, Nesbitt SJ, Schachner ER, Bever GS, Joyce WG. 2011. The bipedal stem crocodilian Poposaurus gracilis: inferring function in fossils and innovation in archosaur locomotion. Bulletin of the Peabody Museum of Natural History 52:107-126.

Goloboff PA, Farris JS, Nixon K. 2003. TNT: tree analysis using new technologies. Program and documentation available from the authors. Available at http://www.zmuc.dk/public/phylogeny (accessed 19 July 2014)

Goloboff PA, Farris JS, Nixon K. 2008. TNT: a free program for phylogenetic analysis.

Cladistics 24:774-786.

Gow CE. 1975. The morphology and relationships of Youngina capensis Broom and Prolacerta broomi Parrington. Palaeontologia africana 18:89-131.

Gower DJ. 1999. Cranial osteology of a new rauisuchian archosaur from the Middle Triassic of southern Germany. Stuttgarter Beiträge zur Naturkunde B 280:1-9.

Gower DJ. 2000. Rauisuchian archosaurs (Reptilia, Diapsida): an overview. Neues Jahrbuch für Geologie und Paläontologie Abhandlungen 218:447-488.

Gower DJ. 2003.Osteology of the early archosaurian reptile Erythrosuchus africanus Broom. Annals of the South African Museum 111:1-88. 
1240 Gower DJ, Schoch R. 2009. Postcranial anatomy of the rauisuchian archosaur Batrachotomus

1241 kupferzellensis. Journal of Vertebrate Paleontology 29:103-122.

1243 Gower DJ, Sennikov AG. 2000. Early archosaurs from Russia. In: Benton MJ, Shishkin MA,

1244 Unwin DM, Kurochkin EN, eds. The age of dinosaurs in Russia and Mongolia. New York:

1245 Cambridge University Press, 140-159.

1246

1247

Gower DJ, Wilkinson M. 1996. Is there any consensus on basal archosaur phylogeny?

1248

1249

1250

1251

Proceedings of Royal Society of London B 263:1399-1406.

Hancox PJ. 1998. A stratigraphic, sedimentological and palaeonvironmental synthesis of the

Beaufort-Molteno contact in the Karoo Basin. Ph.D. thesis, University of the Witwatersrand.

Hancox PJ. 2000. The continental Triassic of South Africa. Zentralblatt für Geologie und

Paläontologie Teil I, 1998:1285-1324.

1257

1258

1259

1260

1261

1262

1263

1264

1265

1266

1267

1268

1269

1270

1271

1272

1273

1274

1275

1276

1277

1278
Huene F von.1920. Osteologie von Aëtosaurus ferratus O. Fraas. Acta Zoologica 1:465-491.

Huene F von. 1946. Die großen Stämme der Tetrapoden in den geologischen Zeiten. Biologisches Zentralblatt 65:268-275.

Huene F von. 1956. Paläontologie und Phylogenie der niederen Tetrapoden. Jena: VEB Gustav Fischer Verlag.

Hutchinson JR. 2001a. The evolution of pelvic osteology and soft tissues on the line to extant birds (Neornithes). Zoological Journal of the Linnean Society 131:123-168.

Hutchinson JR. 2001b. The evolution of femoral osteology and soft tissues on the line to extant birds (Neornithes). Zoological Journal of the Linnean Society 131:169-197.

Krebs B. 1965. Die Triasfauna der Tessiner Kalkalpen. XIX. Ticinosuchus ferox, nov. gen. nov. sp. Ein neuer Pseudosuchier aus der Trias des Monte San Giorgio. Schweizerische

Paläontologische Abhandlungen 81:1-140. 
1279 Krebs B. 1976. Pseudosuchia. In: Kuhn O, ed. Handbuch der Paläoherpetologie. Stuttgart/New 1280 York: Gustav Fischer Verlag. 40-98.

1281

1282 Kuhn O. 1976. Handbuch der Paläoherpetologie. Stuttgart/New York: Gustav Fischer Verlag. 
1283 Lautenschlager S. 2008. Revision of Rauisuchus tiradentes (Archosauria: Rauisuchia) from the

1284 Late Triassic (Carnian) Santa Maria Formation of Brazil and its implications for rauisuchian

1285 phylogeny. Ph.D. thesis, Ludwig Maximilian University of Munich.

1286

1287

1288

1289

1290

1291

1292

1293

1294

1295

1296

1297

1298

1299

1300

1301

1302

1303

1304

1305

1306

1307

1308

1309

1310

1311

1312

1313

1314

1315

1316

1317

1318

1319

1320

1321

1322
Lautenschlager S., Desojo JB. 2011. Reassessment of the Middle Triassic rauisuchian archosaurs

Ticinosuchus ferox and Stagonosuchus nyassicus. Paläontologische Zeitschrift 85:357-381.

Liu J, Zhao Y, Liu X, Wang Y, Liu X. 2012. Rapid exhumation of basement rocks along the northern margin of the North China craton in the Early Jurassic: evidence from the Xiabancheng Basin, Yanshan Tectonic Belt. Basin Research 24:544-558.

Liu J, Li L, Li X-W. 2013. SHRIMP U-Pb zircon dating of the Triassic Ermaying and Tongchuan formations in Shanxi, China and its stratigraphic implications. Vertebrata Palasiatica 51:162168.

Lecuona A, Desojo JB. 2011. Hind limb osteology of Gracilisuchus stipanicicorum (Archosauria: Pseudosuchia). Earth and Environmental Transactions of the Royal Society of Edinburgh 102: $105-128$.

Lucas SG. 1998. Global Triassic tetrapod biostratigraphy and biochronology. Palaeontology, Palaeoclimatology, Palaeoecology 143:347-384.

Lucas SG. 2001. Chinese fossil vertebrates. New York: Columbia University Press.

Lucas SG. 2010. The Triassic timescale based on nonmarine tetrapod biostratigraphy and biochronology. In: Lucas SG, ed. The Triassic timescale. London: Geological Society, Special Publications 334, 447-500.

Lucas SG, Hunt AP. 1993. Fukangolepis Yang, 1978 from the Triassic of China is not an aetosaur. Journal of Vertebrate Paleontology 13:145-147.

Maidment SCR, Barrett P M. 2011. The locomotor musculature of basal ornithischian dinosaurs. Journal of Vertebrate Paleontology 31:1265-1291.

Marugán-Lobón J, Buscalioni ÁD. 2003. Disparity and geometry of the skull in Archosauria (Reptilia: Diapsida). Zoological Journal of the Linnean Society 80:67-88.

Nesbitt SJ. 2003. Arizonasaurus and its implications for archosaur divergence. Proceedings of the Royal Society of London B. 270:234-237. 
1323 Nesbitt SJ. 2009. The osteology and relationships of Vancleavea campi (Reptilia:

1324 Archosauriformes). Zoological Journal of the Linnean Society. 157: 814-864.

1325

1326

1327

1328

1329

1330

1331

1332

1333

1334

1335

1336

1337

1338

1339

1340

1341

1342

1343

1344

1345

1346

1347

1348

1349

1350

1351

1352

1353

1354

1355

1356

1357

1358

1359

1360

1361

1362
Nesbitt SJ. 2011. The early evolution of archosaurs: relationships and the origin of major clades.

Bulletin of the American Museum of Natural History 352:1-292.

Nesbitt SJ, Liu J, Li C. 2011. A sail-backed suchian from the Heshanggou Formation (Early

Triassic: Olenekian) of China. Earth and Environmental Science Transactions of the Royal

Society of Edinburgh 110:271-284.

Nesbitt SJ, Brusatte SL, Desojo J B, Liparini A, De França MA, Weinbaum J C, Gower D J.

2013. Rauisuchia. In: Nesbitt SJ, Desojo BJ, Irmis RB, eds. Anatomy, phylogeny and

palaeobiology of early archosaurs and their kin. London: Geological Society, Special

Publications 379, 241-274.

Norman DB, Weishampel DB. 1991. Feeding mechanisms in some small herbivorous dinosaurs:

processes and patterns. In: Rayner JMV, Wootton RJ, eds. Biomechanics in evolution. Cambridge:

Cambridge University Press, 161-181.

Ogg JG. 2012. Triassic. In: Gradstein FM, Ogg JG, Schmitz MD, Ogg GM, eds. The Geologic

Time Scale 2012. Amsterdam: Elsevier, 681-730.

Parrish JM. 1986. Locomotor adaptations in the hindlimb and pelvis of Thecodontia. Hunteria $1: 1-35$.

Parrish JM. 1992. Phylogeny of the Erythrosuchidae (Reptilia: Archosauriformes). Journal of Vertebrate Paleontology 12:93-102.

Parrish MJ. 1993. Phylogeny of the Crocodylotarsi, with reference to archosaurian and crurotarsan monophyly. Journal of Vertebrate Paleontology 13:287-308.

Parrish J M. 1997. Archosauria. In: Currie PJ, Padian K, eds. Encyclopedia of dinosaurs. London: Academic Press, 20-24.

Perry SF. 1992. Gas exchange strategies in reptiles and the origin of the avian lung. In: Wood SC, Weber RE, Hargens AR, Millard RW, eds. Physiological adaptations in vertebrates: respiration, circulation, and metabolism. New York: Marcel Dekker, 149-167.

Rauhut OWM. 2003. The interrelationships and evolution of basal theropod dinosaurs. Special Papers in Palaeontology 69:1-213. 
1363

1364

1365

1366

1367

1368

1369

1370

1371

1372

1373

1374

1375

1376

1377

1378

1379

1380

1381

1382

1383

1384

1385

1386

1387

1388

1389

1390

1391

1392

1393

1394

1395

1396

1397

1398

1399

1400

1401

1402

1403

Remes K. 2007. Evolution of the pectoral girdle and forelimb in Sauropodomorpha (Dinosauria, Saurischia): osteology, myology and function. Ph.D. thesis, Ludwig Maximilian University of Munich.

Renaut AJ, Hancox PJ. 2001.Redescription of Kannemeyeria argentinensis (Therapsida, Dicynodontia). Palaeontologia africana 37:81-91.

Rewcastle SC. 1980. Form and function in lacertilian knee and mesotarsaljoints: a contribution to the analysis of sprawling locomotion. Journal of Zoology 191:147-170.

de Ricqlès A, Padian K, Knoll F, Horner J R. 2008. On the origin of high growth rates in archosaurs and their ancient relatives: complementary histological studies on Triassic archosauriforms and the problem of a "phylogenetic signal" in bone histology. Annales de Paléontologie 94:57-76.

Romer AS. 1923. Crocodilian pelvic muscles and their avian and reptilian homologues. Bulletin of the American Museum of Natural History 48:533-552.

Romer AS. 1942. The development of tetrapod limb musculature-the thigh of Lacerta. Journal of Morphology 71:251-298.

Romer AS. 1956. Osteology of the Reptiles. Chicago: University of Chicago Press.

Romer AS. 1971. The Chañares (Argentina) Triassic reptile fauna. XI. Two new long-snouted thecodonts, Chanaresuchus and Gualosuchus. Breviora 379:1-22.

Romer AS. 1972a. The Chañares (Argentina) Triassic reptile fauna. XII. The postcranial skeleton of the thecodont Chanaresuchus. Breviora 385:1-21.

Romer AS. 1972b.The Chañares (Argentina) Triassic reptile fauna. XIII. An early ornithosuchid pseudosuchian, Gracilisuchus stipanicicorum, gen. et sp. nov. Breviora 389:1-24.

Romer AS. 1972c. The Chañares (Argentina) Triassic reptile fauna. XVI. Thecodont classification. Breviora 395:1-24.

Rubidge BS. 2005. Re-uniting lost continents - fossil reptiles from the ancient Karoo and their wanderlust. South African Journal of Geology 108:135-172.

Santi G. 1993. Functional bipedalism in some Permo-Triassic extinct reptiles: a possible scale of the degree of efficiency. Studi Trentini di Scienze Naturali Acta Biologica 68:267-280. 
1404

1405

1406

1407

1408

1409

1410

1411

1412

1413

1414

1415

1416

1417

1418

1419

1420

1421

1422

1423

1424

1425

1426

1427

1428

1429

1430

1431

1432

1433

1434

1435

1436

1437

1438

1439

1440

1441

1442

1443

1444

Schachner ER, Manning PL, Dodson P. 2011. Pelvic and hindlimb myology of the basal

archosaur Poposaurus gracilis (Archosauria: Poposauroidea). Journal of Morphology 272:14641491.

Schoch RR, Sues H-D. 2013. A new archosauriform reptile from the Middle Triassic (Ladinian) of Germany. Journal of Systematic Palaeontology 12:113-131.

Sennikov AG. 1989a. Novyy euparkeriid (Thecodontia) iz srednego triasa Yuzhnogo Priural'ya. Paleontologicheskiy Zhurnal 1989:71-78.

Sennikov AG. 1989b. A new euparkeriid (Thecodontia) from the Middle Triassic of the Southern Urals. Paleontological Journal 22:66-73.

Seymour RS, Bennett-Stamper CL, Johnston SD, Carrier DR, Grigg GC. 2004. Evidence for endothermic ancestors of crocodiles at the stem of archosaur evolution. Physiological and Biochemical Zoology 77:1051-1067.

Shubin NH, Sues HD. 1991. Biogeography of early Mesozoic continental tetrapods: patterns and implications. Paleobiology 214-230.

Sookias RB, Butler RJ. 2013. Euparkeriidae. In: Nesbitt SJ, Desojo JB, Irmis RB, eds. Anatomy, phylogeny and palaeobiology of early archosaurs and their kin. London: Geological Society, Special Publications, 379: 35-48.

Sookias RB, Sennikov AG, Gower DJ, Butler RJ (in press). The monophyly of Euparkeriidae (Reptilia: Archosauriformes) and the origins of crown Archosauria: a revision of Dorosuchus neoetus from the Middle Triassic of Russia. Palaeontology (published online).

Spielmann JA, Lucas SG, Rinehart LF, Heckert AB. 2008. The Late Triassic archosauromorph Trilophosaurus. New Mexico Museum of Natural History and Science Bulletin 43, 1-177.

Sues H-D, Fraser NC. 2010. Triassic Life on Land: the Great Transition. New York: Columbia University Press.

Sullivan C. 2010. The role of the calcaneal 'heel' as a propulsive lever in basal archosaurs and extant monitor lizards. Journal of Vertebrate Paleontology 30:1422-1432.

Welles SP, Long RA. 1974.The tarsus of theropod dinosaurs. Annals of the South African Museum 64:191-218. 
1445 Wilson JA. 1999. A nomenclature for vertebral laminae in sauropods and other saurischian

1446

1447

1448

1449

1450

1451

1452

1453

1454

1455

1456

1457

1458

1459

1460

1461

1462

1463

1464

1465

1466

1467

1468

1469

1470

1471

1472

1473

1474

1475

1476

1477

1478

1479

1480

1481

1482

1483

1484

1485 dinosaurs. Journal of Vertebrate Paleontology 19:639-653.

Wilson JA, D’Emic MD, Ikejiri T, Moacdieh EM, Whitlock JA. 2011. A nomenclature for vertebral fossae in sauropods and other saurischian dinosaurs. PLoS ONE 6:e17114.

Wu X. 1981. The discovery of a new thecodont form North-East Shensi. Vertebrata PalAsiatica 19:122-132. (in Chinese with English summary)

Wu X. 1982. The pseudosuchian reptiles from Shan-Gan-Ning basin. Vertebrata PalAsiatica 20:289-301. (in Chinese with English summary)

Wu X-C, Liu J, Li J. 2001.The anatomy of the first archosauriform (Diapsida) from the terrestrial Upper Triassic of China. Vertebrata PalAsiatica 39:251-265.

Wu X-C, Russell AP. 2001. Redescription of Turfanosuchus dabanensis (Archosauriformes) and new information on its phylogenetic relationships. Journal of Vertebrate Paleontology 21:40-50.

Wu X-C, Sues H-D. 1996. Reassessment of Platyognathus hsui Young, 1944 (Archosauria:

Crocodyliformes) from the Lower Lufeng Formation (Lower Jurassic) of Yunnan, China. Journal of Vertebrate Paleontology 16:42-48.

Wu X, Sun A. 2008. Infraclass Archosauromorpha. In: Li J, Wu X, Zhang F, eds. 2008. The Chinese fossil reptiles and their kin. Beijing: Science Press, 167-214.

Yin H-f. 2003. Triassic Biostratigraphy of China. In: Zhang W, Chen P-j, Palmer AR, eds. Biostratigraphy of China. Beijing: Science Press, 379-422.

Young CC [Yang Z]. 1944. On a supposed new pseudosuchian from Upper Triassic saurischianbearing Red Beds of Lufeng, Yunnan, China. American Museum Novitates 1264:1-4.

Young CC [Yang Z]. 1964. The pseudosuchians in China. Palaeontologia Sinica 151:1-205. Young CC [Yang Z]. 1973. On a new pseudosuchian from Turfan, Sinkiang. Memoirs of the Institute of Vertebrate Palaeontology and Paleoanthropology Academia Sinica 10:15-38. Young CC [Yang Z]. 1978. A Late Triassic vertebrate fauna from Fu-kang, Sinkiang. Memoirs of the Institute of Vertebrate Paleontology and Paleoanthropology Academia Sinica 13:60-67.

Zhen S, Zhen B, Master NJ, Lucas SG. 1985. The Mesozoic reptiles of China. In: Lucas SG, Master NJ, eds. Studies of Chinese fossil vertebrates. Uppsala: Bulletin of the Geological 
1486

1487

1488

1489

1490

1491

1492

1493

1494

1495

1496

1497

1498

1499

1500

1501

1502

1503

1504

1505

1506

1507

1508

1509

1510

1511

1512

1513

1514

1515

1516

1517

1518

1519

1520

1521

Institutions of the University of Uppsala, 11, 133-150.

\section{Figure captions}

Figure 1. Localities of the putative Chinese euparkeriids. Map of China, with inset of region, showing the localities where the holotype specimens of the three Chinese putative euparkeriid taxa reassessed in this paper were collected. White=People's Republic of China; light grey=other countries; dark grey=ocean; thick grey lines=national borders; thin grey lines (grey lines in inset)=province borders; thin black lines (inset only)=roads; black circles (inset only)=major settlements; stars=localities.

Figure 2. Holotype and paratypes of 'Wangisuchus tzeyii' nomen dubium. Holotype IVPP V2701, left maxilla, in medial (A) and lateral (B) views. Paratypes, right maxillae, in lateral views: IVPP V2702 (C); IVPP V2703 (D); IVPP V2704 (E). adm, anterodorsal margin, al, alveolus, aofo, antorbital fossa, idp, interdental plate, mas, ascending process of the maxilla, $t$, tooth.

Figure 3. Cervical and dorsal vertebrae of Halazhaisuchus qiaoensis and cervical vertebrae of 'Turfanosuchus shageduensis' nomen dubium. Posterior three cervical and anterior three dorsal vertebrae of Halazhaisuchus qiaoensis IVPP V6027-1 in right lateral (A), dorsal (B; osteoderms visible), ventral (C), anterior (D) and posterior (E) views; series of dorsal vertebrae of Halazhaisuchus qiaoensis IVPP V6027-2 in right lateral (F), dorsal (G; osteoderms visible), ventral (H), anterior (I) and posterior (J) views; cervical vertebrae of 'Turfanosuchus shageduensis' IVPP V6028-2 in right lateral (K; broken segments disarticulated), ventral (L), dorsal $(\mathrm{M})$, anterior $(\mathrm{N})$ and posterior $(\mathrm{O})$ views. acpl, anterior centroparapophyseal lamina, di, diapophysis, ep, epipophysis, ic, intercentrum, ns, neural spine, ost, osteoderm, pa, parapophysis, ppdl, paradiapophyseal lamina, prdl, prezygodiapophyseal lamina, sdf, spinodiapophyseal fossa, tp, transverse process.

Figure 4. Ribs and osteoderms of Halazhaisuchus qiaoensis compared with other taxa. Right cervical rib of Halazhaisuchus qiaoensis IVPP V6027-9 in dorsal (A) and ventral (B) views; left cervical rib (image mirrored for comparison) of Batrachotomus kupferzellensis SMNS 91046 in dorsal (C) and ventral (D) views; right paramedian osteoderm of Halazhaisuchus qiaoensis IVPP V6027-8 in dorsal (E) and ventral (F) views; right paramedian osteoderm of Euparkeria capensis UMZC T692j in dorsal $(\mathrm{G})$ and ventral $(\mathrm{H})$ views; paramedian osteoderms in articulation of Halazhaisuchus qiaoensis IVPP V6027-1 in dorsal (I) view (right is anterior). cap, capitulum, fl, 
1522 flange, k, keel, tub, tuberculum.

1523

1524 Figure 5. Scapulae and coracoids of Halazhaisuchus qiaoensis and 'Turfanosuchus

1525 shageduensis' nomen dubium. Left scapula and coracoid of Halazhaisuchus qiaoensis IVPP

1526 V6027-3 in lateral (A) and medial (B) views, right scapula and partial coracoid Halazhaisuchus

1527 qiaoensis IVPP V6027-4 in lateral (C) and medial (D) views, and left scapula and coracoid of

1528 'Turfanosuchus shageduensis' IVPP V6028-3 in lateral (E) and medial (F) views. acr, acromion

1529 process, cof, coracoid foramen, dls, depressed lateral surface, gl, glenoid, mar, muscle attachment

1530 ridge, tu, tuber.

1531

1532 Figure 6. Right humeri of Halazhaisuchus qiaoensis and 'Turfanosuchus shageduensis'

1533 nomen dubium. Halazhaisuchus qiaoensis IVPP V6027-5 in proximal (A), dorsal (B), lateral

1534 (C), ventral (D), distal (E) and medial (F) views, and ‘Turfanosuchus shageduensis' IVPP

1535 V6028-4 in proximal (G), dorsal (H), lateral (I), ventral (j), distal (K) and medial (L) views.

1536 Arrows indicate dorsal direction. dpc, deltopectoral crest, ect, ectepicondyle, ectg, ectepicondylar

1537 groove, ent, entepicondyle, it, internal tuberosity, sup, supinator process.

1538

1539 Figure 7. Right forelimb epipodials of Halazhaisuchus qiaoensis and 'Turfanosuchus

1540 shageduensis' nomen dubium. Ulna of Halazhaisuchus qiaoensis IVPP V6027-6 in proximal

1541 (A), medial (B), distal (C), lateral (D), dorsal (E), and ventral (F) views; ulna of 'Turfanosuchus

1542 shageduensis' IVPP V6028 in proximal (G), medial (H), distal (I), lateral (J), dorsal (K), and

1543 ventral (L) views; radius of Halazhaisuchus qiaoensis IVPP V6027-7 in proximal (M), medial

$1544(\mathrm{~N})$, distal (O), lateral (P), dorsal (Q), and ventral (R) views; radius of 'Turfanosuchus

1545 shageduensis' IVPP V6028 in proximal (S), medial (T), distal (U), lateral (V), dorsal (W), and

1546 ventral (X) views. Arrows indicate dorsal direction. bev, bevelled surface, fos, fossa, gr, groove,

1547 ol, olecranon, ra, raised area, ri, ridge.

1548

1549 Figure 8. Mandible of 'Turfanosuchus shageduensis' nomen dubium. Right mandible of

1550 holotype of 'Turfanosuchus shageduensis', IVPP V6028-1 in lateral (A), medial (B) and dorsal

1551 (C) views. a, angular, c, coronoid, d, dentary, pra, prearticular, sa, surangular, sp, splenial, step,

1552 step between more dorsal and more ventral sections of prearticular, $t$, teeth.

1553

1554 Figure 9. Femur of 'Turfanosuchus shageduensis' nomen dubium. Right femur of

1555 'Turfanosuchus shageduensis' IVPP V6028-5 in dorsal (A), proximal (B), lateral (C), ventral (D),

1556 medial (E) and distal (F) views. Arrows indicate dorsal direction. ac, adductor crest, cfb, $m$.

1557 caudofemoralis brevis attachment, cfl, m. caudofemoralis longus attachment, ct, crista 
1558 tibiofibularis, fte, $\mathrm{m}$. femorotibialis externus attachment, h, head, ig, intercondylar groove, lc,

1559 lateral condyle, mc, medial condyle, ps, popliteal space, ve, ventral eminence, 4t, fourth

1560 trochanter.

1561

1562

1563

1564

1565

1566

1567

1568

1569

1570

1571

1572

1573

1574

1575

1576

1577

1578

1579

1580

1581

1582

1583

1584

1585

1586

1587

1588

1589

1590

Figure 10. Right hind limb epipodials of 'Turfanosuchus shageduensis' nomen dubium. Tibia of 'Turfanosuchus shageduensis' IVPP V6028-6 in proximal (A), dorsal (B), distal (C), lateral (D), ventral (E) and medial (F) views; fibula of 'Turfanosuchus shageduensis' IVPP V6028 in dorsal $(\mathrm{G})$, distal $(\mathrm{H})$, proximal (I), lateral (J), ventral (K) and medial (L) views. Arrows indicate dorsal direction. cn, cnemial crest, lc, lateral condyle, m.if, m. iliofibularis attachment, pc, posterior condyle, ri, ridge, step, step between more medial and more lateral surfaces, ?gr, possible groove.

Figure 11. Phylogenetic position of Halazhaisuchus qiaoensis and 'Turfanosuchus shageduensis' nomen dubium. Strict consensus of 810 most parsimonious trees of length 1257 steps, showing the phylogenetic positions of Halazhaisuchus qiaoensis and 'Turfanosuchus shageduensis'. Consistency index $=0.384$; retention index $=0.793$. Numbers below nodes are bootstrap values (before the slash) and decay indices (after the slash) for the nodes in question.

\section{SI Captions}

Table S1. Supplementary table of measurements. Measurements holotypes of Halazhaisuchus qiaoensis and 'Turfanosuchus shageduensis' and of holotype and paratypes of "Wangisuchus tzeyii",.

Table S2. Supplementary table of Chinese names. Names of localities, towns, administrative divisions and formations used in this article, showing their equivalents in simplified Chinese, Pinyin, and previously published romanizations and translations.

Matrix S1. Character matrix. Matrix based on that of Butler et al. (2014) with scores for Halazhaisuchus qiaoensis and 'Turfanosuchus shageduensis', as well as for a single Halazhaisuchus qiaoensis OTU incorporating 'Turfanosuchus shageduensis' as a junior subjective synonym. 


\section{Figure 1}

Figure 1. Localities of the putative Chinese euparkeriids.

Map of China, with inset of region, showing the localities where the holotype specimens of the three Chinese putative euparkeriid taxa reassessed in this paper were collected. White=People's Republic of China; light grey=other countries; dark grey=ocean; thick grey lines=national borders; thin grey lines (grey lines in inset)=province borders; thin black lines (inset only)=roads; black circles (inset only)=major settlements; stars=localities. Provinces names are in capital letters. 


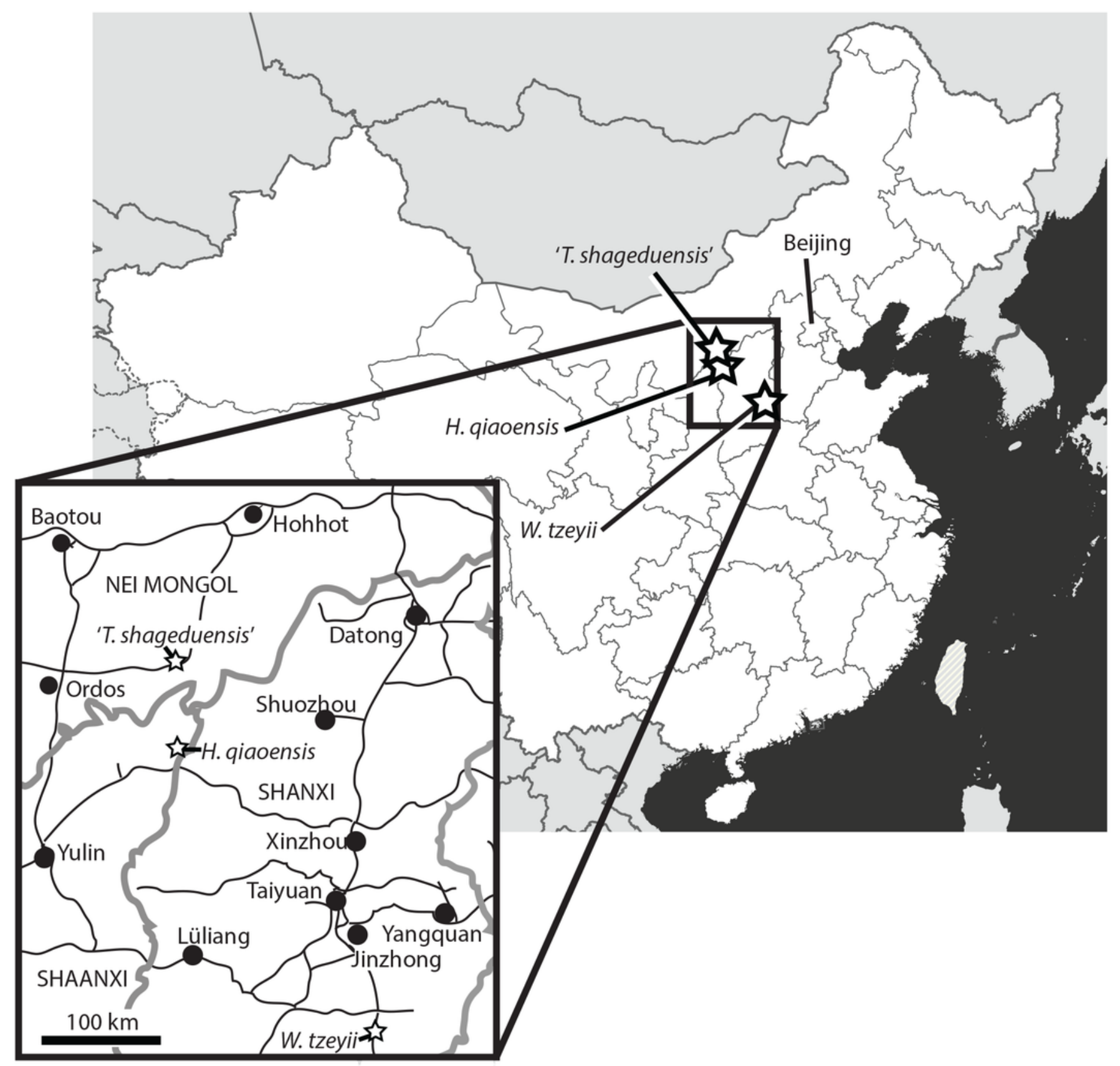


Figure 2

Figure 2. Holotype and paratypes of 'Wangisuchus tzeyii' nomen dubium.

Holotype IVPP V2701, left maxilla, in medial (A) and lateral (B) views. Paratypes, right maxillae, in lateral views: IVPP V2702 (C); IVPP V2703 (D); IVPP V2704 (E). adm, anterodorsal margin, al, alveolus, aofo, antorbital fossa, idp, interdental plate, mas, ascending process of the maxilla, $t$, tooth. 


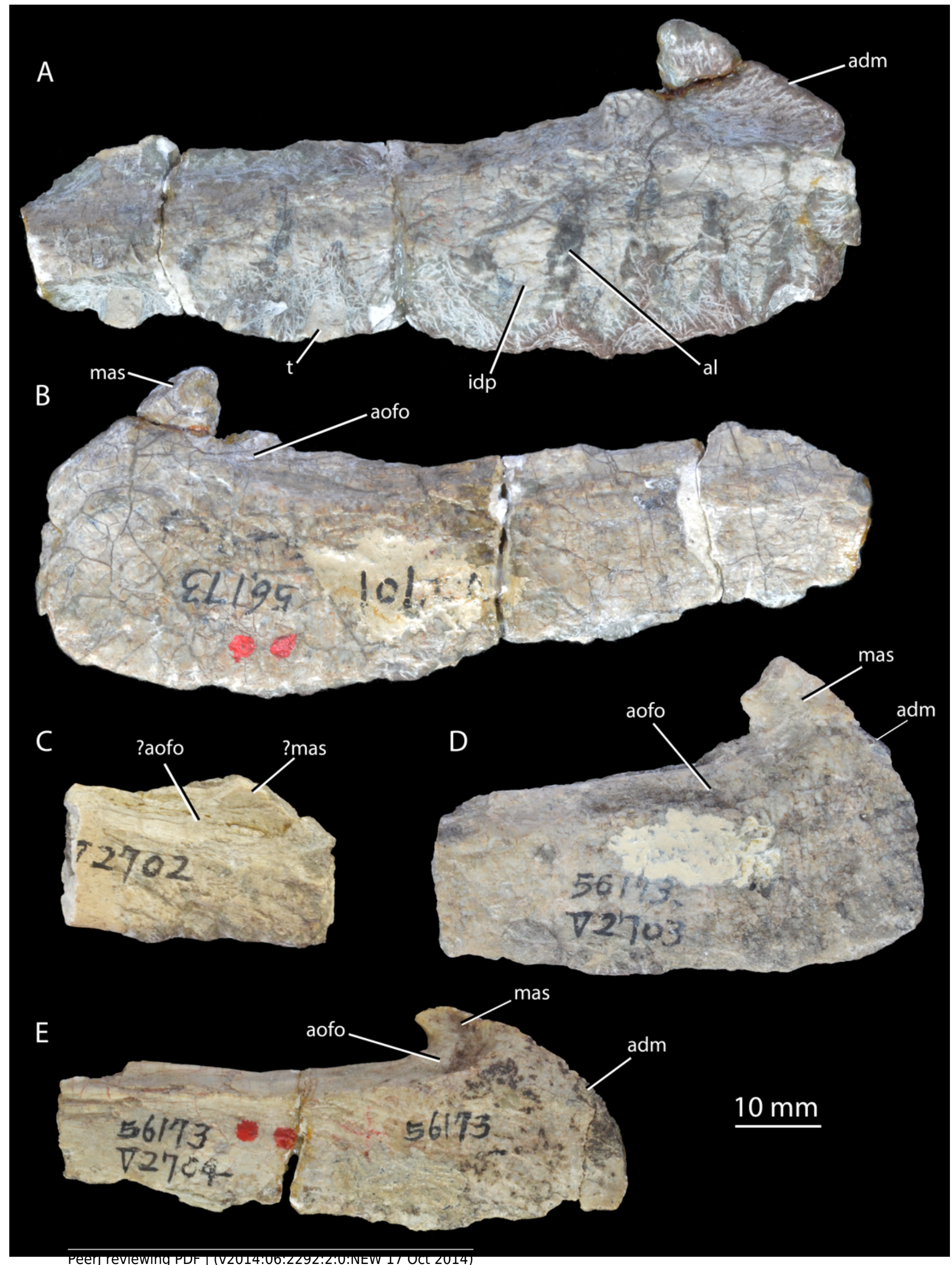




\section{Figure 3}

Figure 3. Cervical and dorsal vertebrae of Halazhaisuchus qiaoensis and cervical vertebrae of 'Turfanosuchus shageduensis' nomen dubium.

Posterior three cervical and anterior three dorsal vertebrae of Halazhaisuchus qiaoensis IVPP V6027-1 in right lateral (A), dorsal (B; osteoderms visible), ventral (C), anterior (D) and posterior (E) views; series of dorsal vertebrae of Halazhaisuchus qiaoensis IVPP V6027-2 in right lateral (F), dorsal (G; osteoderms visible), ventral (H), anterior (I) and posterior (J) views; cervical vertebrae of 'Turfanosuchus shageduensis' IVPP V6028-2 in right lateral (K; broken segments disarticulated), ventral (L), dorsal (M), anterior (N) and posterior (O) views. acpl, anterior centroparapophyseal lamina, di, diapophysis, ep, epipophysis, ic, intercentrum, ns, neural spine, ost, osteoderm, pa, parapophysis, ppdl, paradiapophyseal lamina, prdl, prezygodiapophyseal lamina, sdf, spinodiapophyseal fossa, tp, transverse process. 


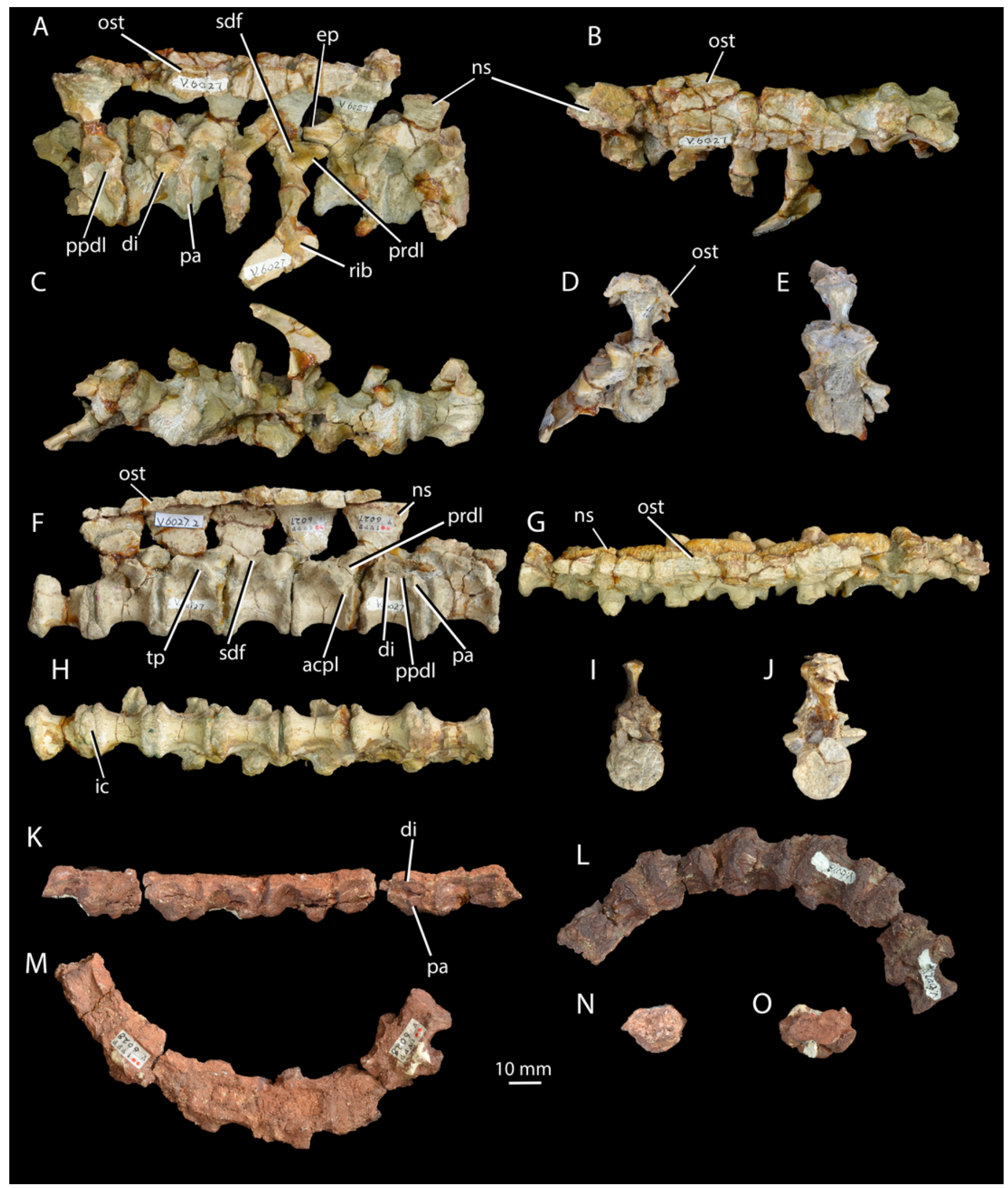




\section{Figure 4}

Figure 4. Ribs and osteoderms of Halazhaisuchus qiaoensis compared with other taxa.

Right cervical rib of Halazhaisuchus qiaoensis IVPP V6027-9 in dorsal (A) and ventral (B) views; left cervical rib (image mirrored for comparison) of Batrachotomus kupferzellensis SMNS 91046 in dorsal (C) and ventral (D) views; right paramedian osteoderm of Halazhaisuchus qiaoensis IVPP V6027-8 in dorsal (E) and ventral (F) views; right paramedian osteoderm of Euparkeria capensis UMZC T692j in dorsal (G) and ventral (H) views; paramedian osteoderms in articulation of Halazhaisuchus qiaoensis IVPP V6027-1 in dorsal (I) view (right is anterior). cap, capitulum, fl, flange, $\mathrm{k}$, keel, tub, tuberculum. 


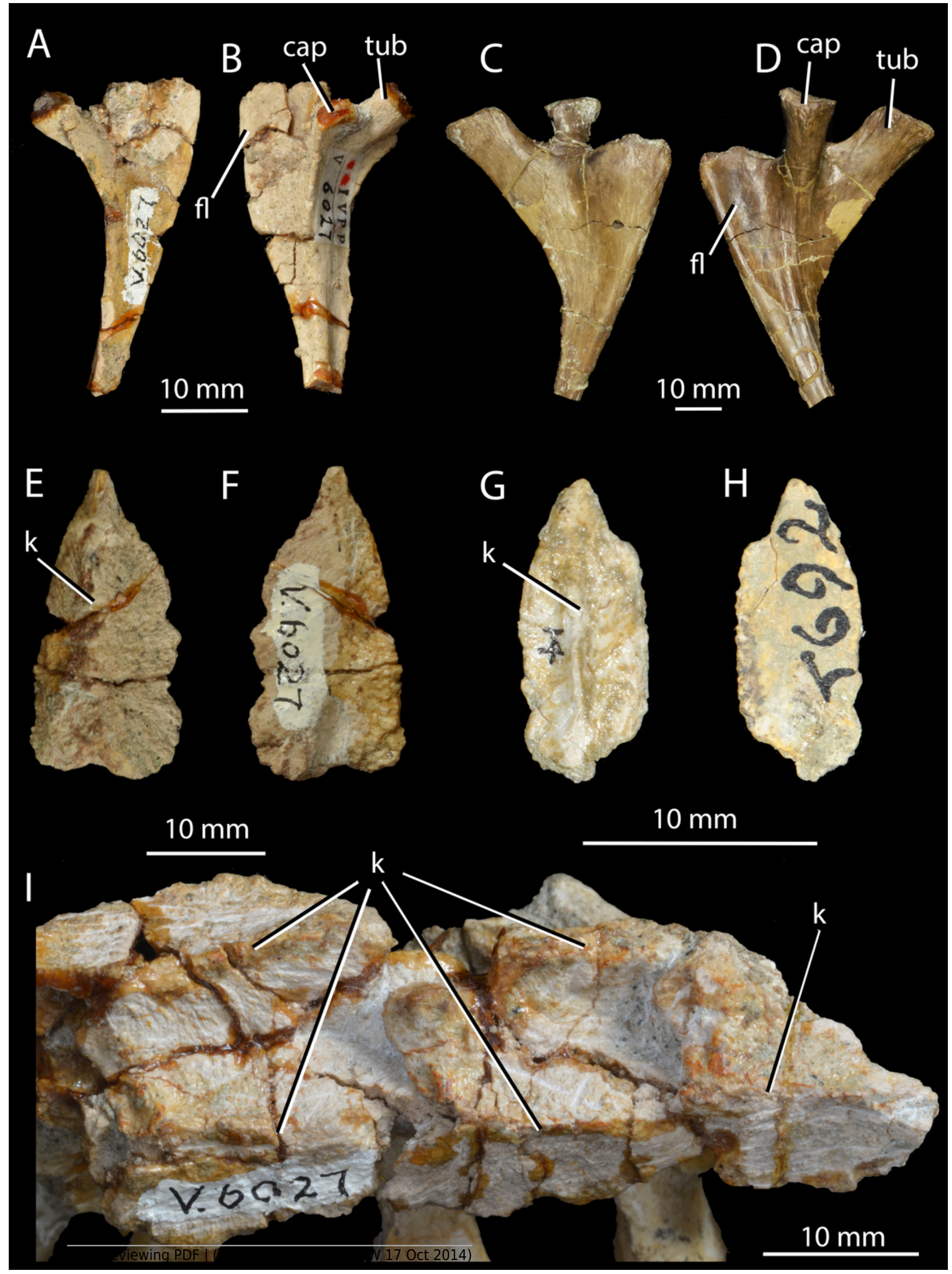


Figure 5

Figure 5. Scapulae and coracoids of Halazhaisuchus qiaoensis and 'Turfanosuchus shageduensis' nomen dubium.

Left scapula and coracoid of Halazhaisuchus qiaoensis IVPP V6027-3 in lateral (A) and medial (B) views, right scapula and partial coracoid Halazhaisuchus qiaoensis IVPP V6027-4 in lateral (C) and medial (D) views, and left scapula and coracoid of 'Turfanosuchus shageduensis' IVPP V6028-3 in lateral (E) and medial (F) views. acr, acromion process, cof, coracoid foramen, dls, depressed lateral surface, gl, glenoid, mar, muscle attachment ridge, tu, tuber. 


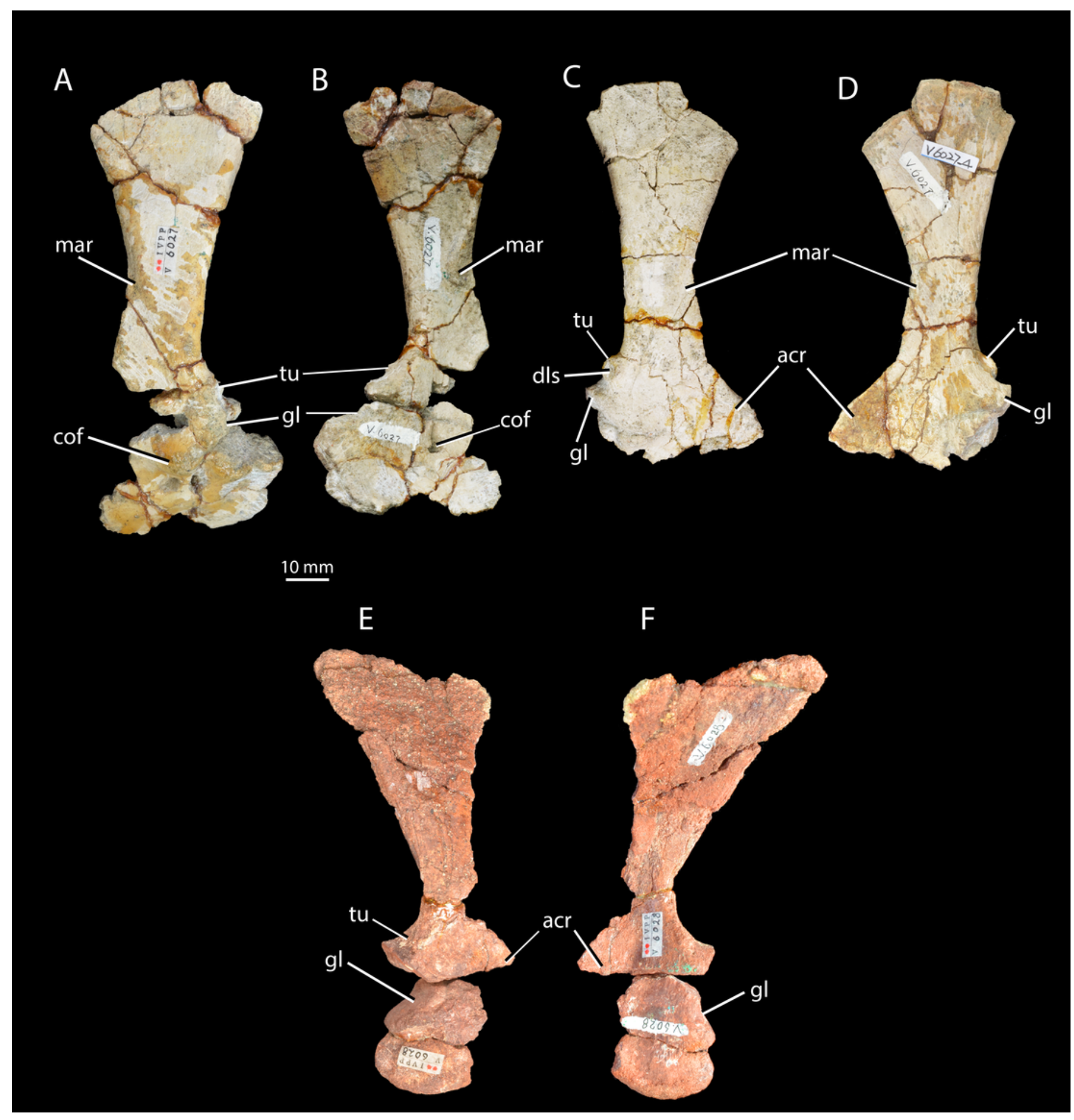




\section{Figure 6}

Figure 6. Right humeri of Halazhaisuchus qiaoensis and 'Turfanosuchus shageduensis' nomen dubium.

Halazhaisuchus qiaoensis IVPP V6027-5 in proximal (A), dorsal (B), lateral (C), ventral (D), distal (E) and medial (F) views, and 'Turfanosuchus shageduensis' IVPP V6028-4 in proximal $(G)$, dorsal $(H)$, lateral $(I)$, ventral $(j)$, distal $(K)$ and medial $(L)$ views. Arrows indicate dorsal direction. dpc, deltopectoral crest, ect, ectepicondyle, ectg, ectepicondylar groove, ent, entepicondyle, it, internal tuberosity, sup, supinator process. 


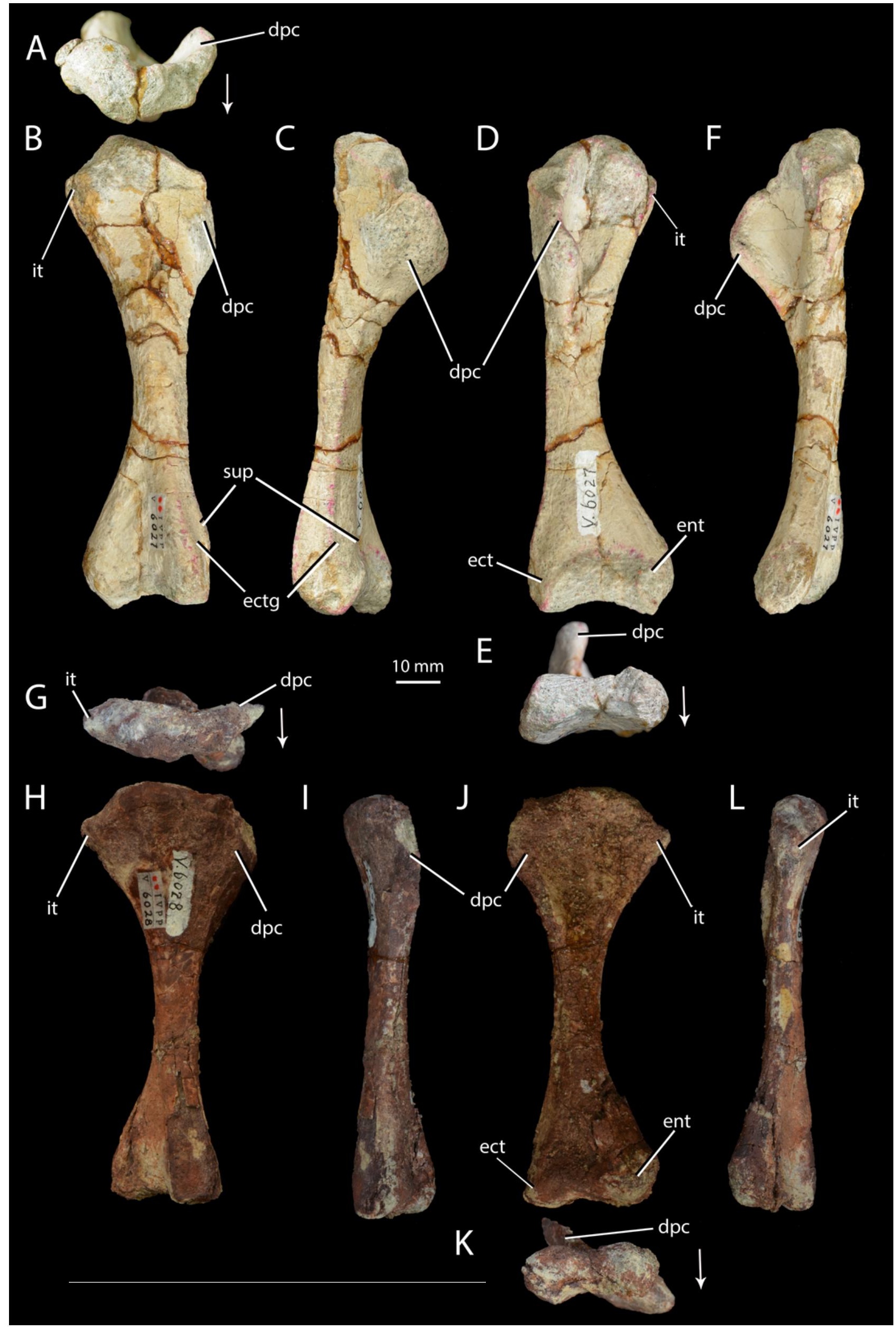




\section{Figure 7}

Figure 7. Right forelimb epipodials of Halazhaisuchus qiaoensis and 'Turfanosuchus shageduensis' nomen dubium.

Ulna of Halazhaisuchus qiaoensis IVPP V6027-6 in proximal (A), medial (B), distal (C), lateral (D), dorsal (E), and ventral (F) views; ulna of 'Turfanosuchus shageduensis' IVPP V6028 in proximal (G), medial $(H)$, distal (I), lateral (J), dorsal (K), and ventral (L) views; radius of Halazhaisuchus qiaoensis IVPP V6027-7 in proximal (M), medial (N), distal (O), lateral (P), dorsal (Q), and ventral (R) views; radius of 'Turfanosuchus shageduensis' IVPP V6028 in proximal $(\mathrm{S})$, medial $(\mathrm{T})$, distal $(\mathrm{U})$, lateral $(\mathrm{V})$, dorsal $(\mathrm{W})$, and ventral $(\mathrm{X})$ views. Arrows indicate dorsal direction. bev, bevelled surface, fos, fossa, gr, groove, ol, olecranon, ra, raised area, ri, ridge. 
PeerJ Reviewing Manuscript

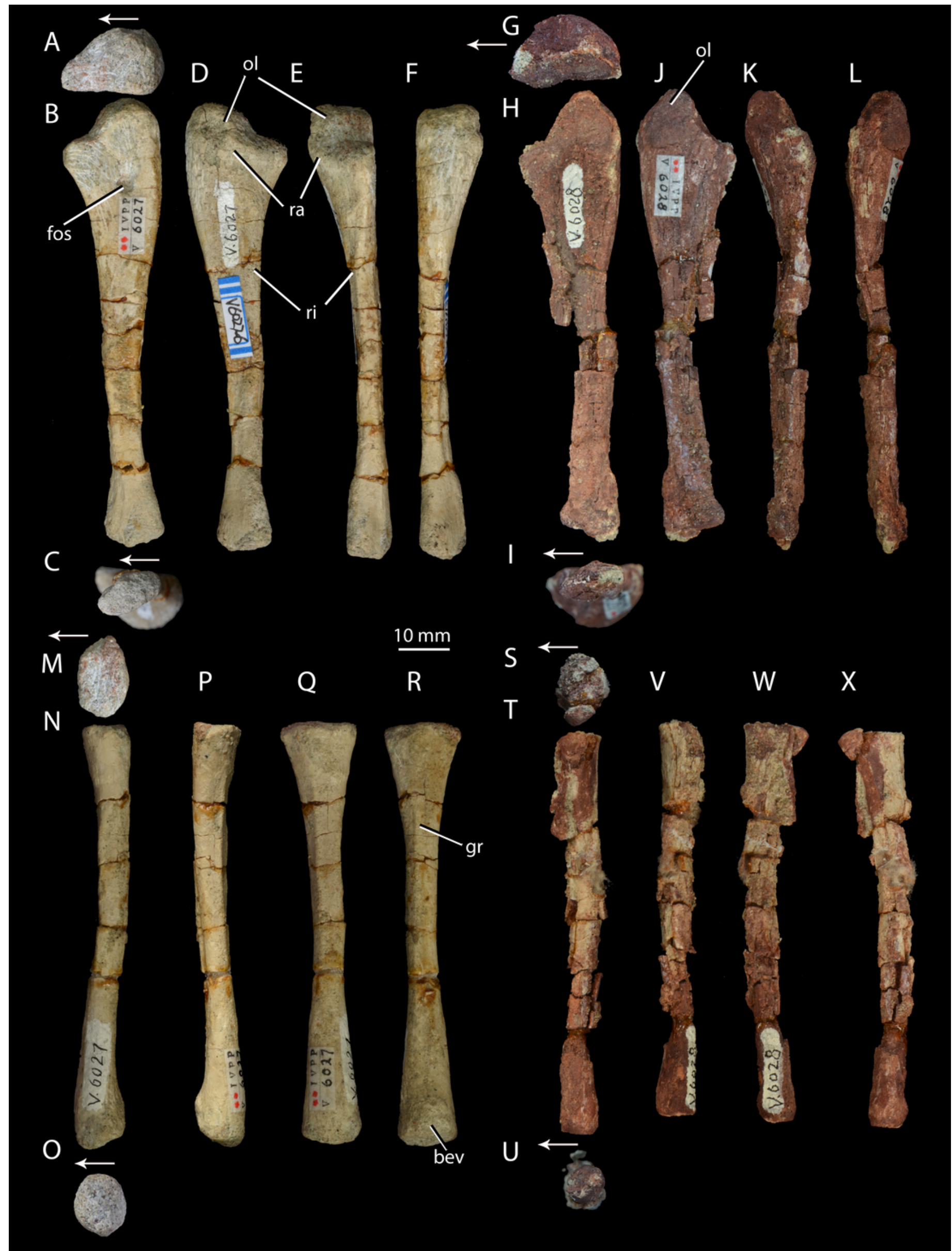




\section{Figure 8}

Figure 8. Mandible of 'Turfanosuchus shageduensis' nomen dubium.

Right mandible of holotype of 'Turfanosuchus shageduensis', IVPP V6028-1 in lateral (A), medial (B) and dorsal (C) views. a, angular, c, coronoid, d, dentary, pra, prearticular, sa, surangular, sp, splenial, step, step between more dorsal and more ventral sections of prearticular, $t$, teeth.

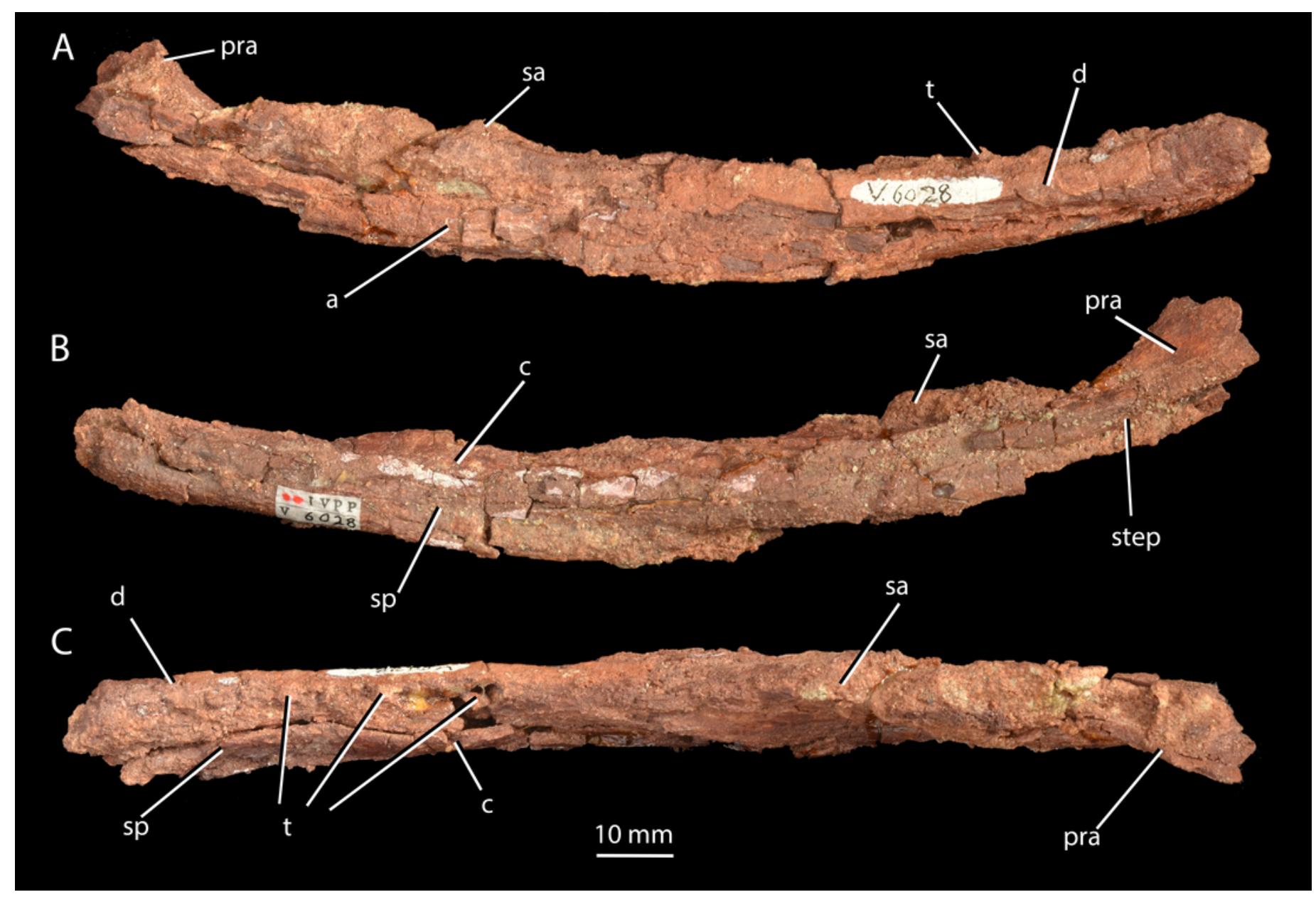




\section{Figure 9}

Figure 9. Femur of 'Turfanosuchus shageduensis' nomen dubium.

Right femur of 'Turfanosuchus shageduensis' IVPP V6028-5 in dorsal (A), proximal (B), lateral $(C)$, ventral $(D)$, medial $(E)$ and distal $(F)$ views. Arrows indicate dorsal direction. ac, adductor crest, cfb, m. caudofemoralis brevis attachment, cfl, m. caudofemoralis longus attachment, ct, crista tibiofibularis, fte, m. femorotibialis externus attachment, h, head, ig, intercondylar groove, lc, lateral condyle, mc, medial condyle, ps, popliteal space, ve, ventral eminence, 4t, fourth trochanter. 


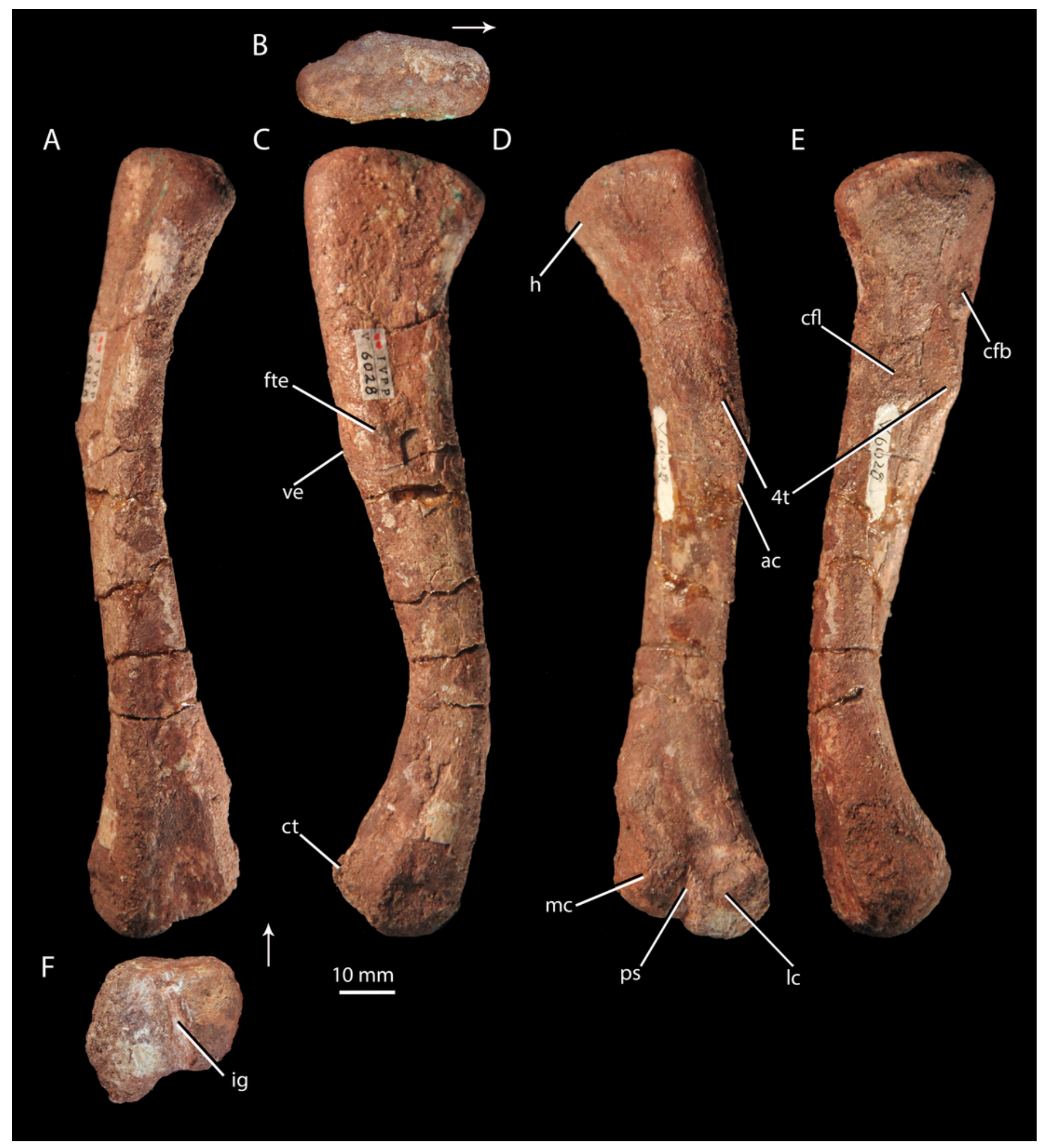




\section{Figure 10}

Figure 10. Right hind limb epipodials of 'Turfanosuchus shageduensis' nomen dubium.

Tibia of 'Turfanosuchus shageduensis' IVPP V6028-6 in proximal (A), dorsal (B), distal (C), lateral (D), ventral (E) and medial (F) views; fibula of 'Turfanosuchus shageduensis' IVPP V6028 in dorsal $(\mathrm{G})$, distal $(\mathrm{H})$, proximal $(\mathrm{I})$, lateral $(\mathrm{J})$, ventral $(\mathrm{K})$ and medial $(\mathrm{L})$ views. Arrows indicate dorsal direction. cn, cnemial crest, lc, lateral condyle, m.if, m. iliofibularis attachment, pc, posterior condyle, ri, ridge, step, step between more medial and more lateral surfaces, ?gr, possible groove. 


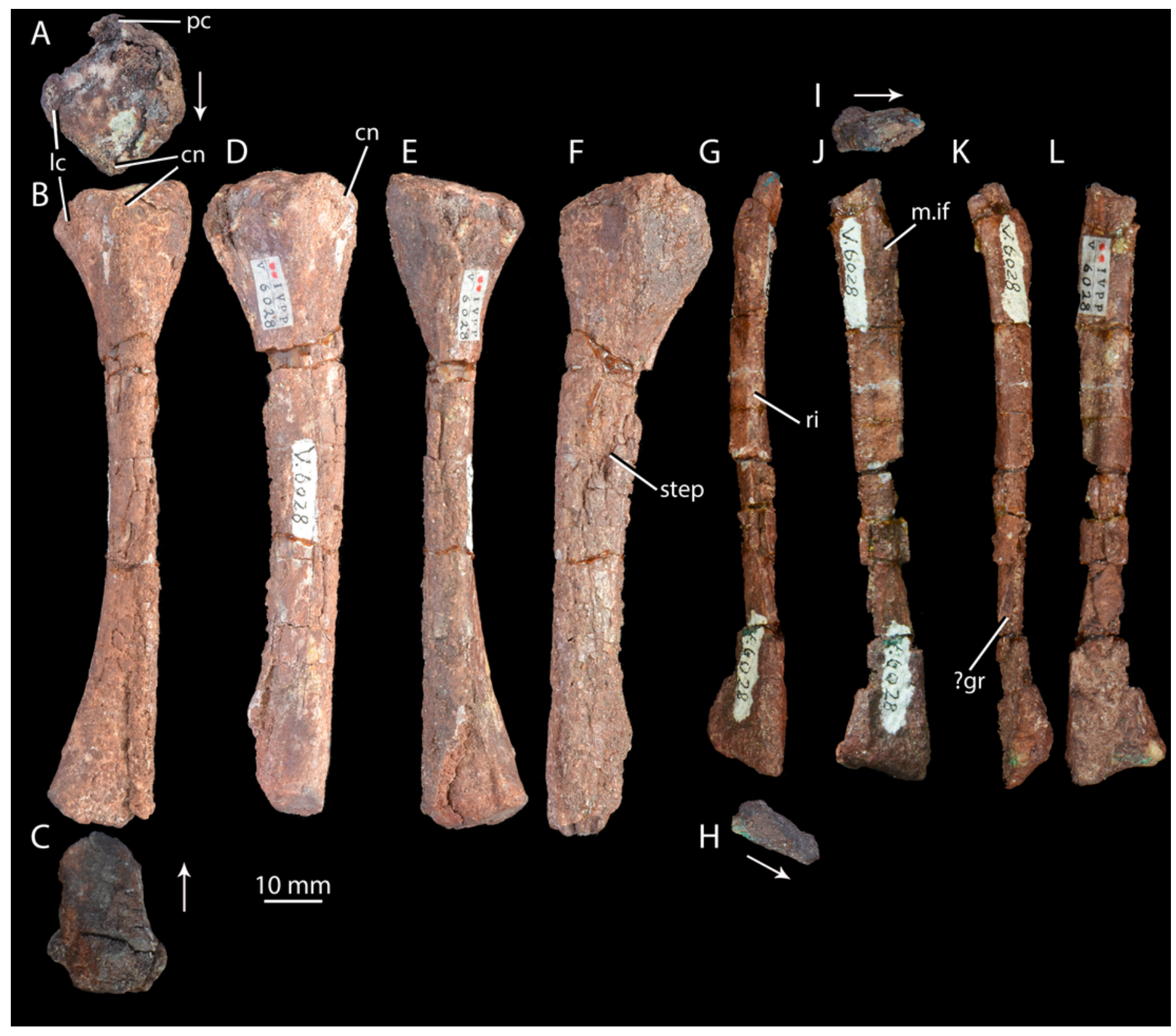




\section{Figure 11}

Figure 11. Phylogenetic position of Halazhaisuchus qiaoensis and 'Turfanosuchus shageduensis' nomen dubium.

Strict consensus of 810 most parsimonious trees of length 1257 steps, showing the phylogenetic positions of Halazhaisuchus qiaoensis and 'Turfanosuchus shageduensis'. Consistency index $=0.384$; retention index $=0.793$. Numbers below nodes are bootstrap values (before the slash) and decay indices (after the slash) for the nodes in question.

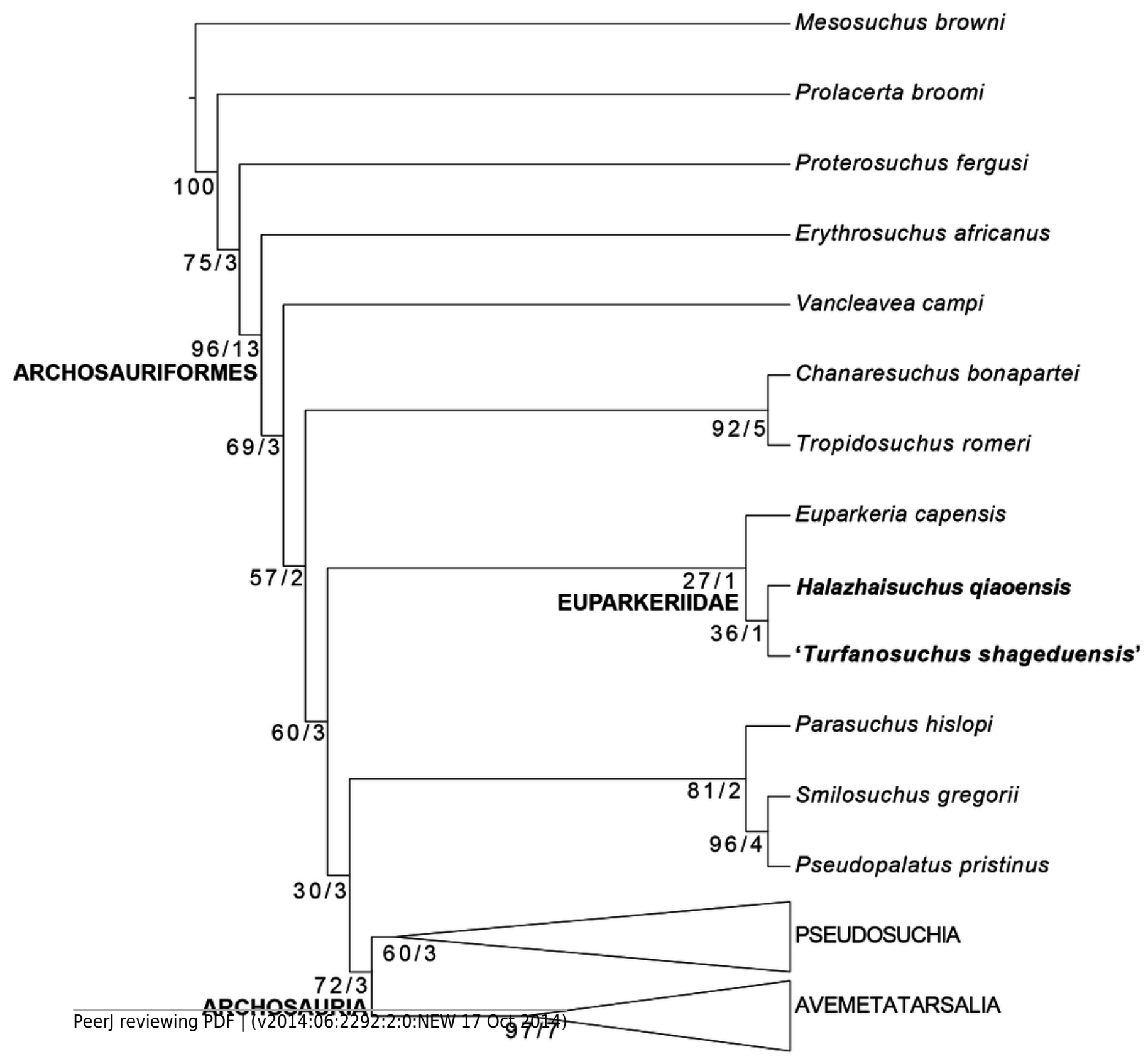

